\title{
Glycomics of bone marrow-derived mesenchymal stem cells can be used to evaluate their cellular differentiation stage
}

\author{
Annamari Heiskanen • Tia Hirvonen • Hanna Salo • \\ Ulla Impola • Anne Olonen • Anita Laitinen • \\ Sari Tiitinen • Suvi Natunen • Olli Aitio • \\ Halina Miller-Podraza • Manfred Wuhrer • \\ André M. Deelder • Jari Natunen • Jarmo Laine • \\ Petri Lehenkari • Juhani Saarinen • Tero Satomaa • \\ Leena Valmu
}

Received: 14 April 2008 /Revised: 15 October 2008 / Accepted: 5 November 2008 / Published online: 27 November 2008

(C) The Author(s) 2008. This article is published with open access at Springerlink.com

\begin{abstract}
Human mesenchymal stem cells (MSCs) are adult multipotent progenitor cells. They hold an enormous therapeutic potential, but at the moment there is little information on the properties of MSCs, including their surface structures. In the present study, we analyzed the mesenchymal stem cell glycome by using mass spectrometric profiling as well as a panel of glycan binding proteins. Structural verifications were obtained by nuclear magnetic resonance spectroscopy, mass spectrometric fragmentation, and glycosidase digestions. The MSC glycome was compared to the glycome of corresponding osteogenically differentiated cells. More than one hundred glycan signals were detected in mesenchymal stem cells and osteoblasts differentiated from them. The glycan profiles of MSCs and osteoblasts were consistently different in biological replicates, indicating that stem cells and osteoblasts have characteristic glycosylation features. Glycosylation features associated with MSCs rather than
\end{abstract}

T. Hirvonen $\cdot$ U. Impola $\cdot$ A. Laitinen $\cdot$ S. Tiitinen $\cdot$ S. Natunen $\cdot$ J. Laine $\cdot$ L. Valmu $(\bowtie)$

Research and Development, Finnish Red Cross Blood Service, Kivihaantie 7,

00310 Helsinki, Finland

e-mail: leena.valmu@veripalvelu.fi

A. Heiskanen · H. Salo · A. Olonen · J. Natunen · J. Saarinen •

T. Satomaa

Glykos Finland Ltd.,

Helsinki, Finland

P. Lehenkari

Clinical Research Center, University of Oulu,

Oulu, Finland differentiated cells included high-mannose type N-glycans, linear poly- $N$-acetyllactosamine chains and $\alpha 2-3$-sialylation. Mesenchymal stem cells expressed SSEA-4 and sialyl Lewis $\mathrm{x}$ epitopes. Characteristic glycosylation features that appeared in differentiated osteoblasts included abundant sulfate ester modifications. The results show that glycosylation analysis can be used to evaluate MSC differentiation state.

Keywords Mesenchymal stem cells · Differentiation · Glycomics · Mass spectrometry Exoglycosidase

$\begin{array}{ll}\text { Abbreviations } & \\ \mathrm{Ab} & \begin{array}{l}\text { antibody } \\ \text { deoxyhexose }\end{array} \\ \mathrm{F} & \text { fluorescein isothiocyanate } \\ \text { FITC } & \begin{array}{l}\text { Fourier transform ion cyclotron resonance } \\ \text { mass spectrometry }\end{array}\end{array}$

O. Aitio

Institute of Biotechnology,

Program of Structural Biology and Biophysics,

University of Helsinki,

Helsinki, Finland

M. Wuhrer $\cdot$ A. M. Deelder

Biomolecular Mass Spectrometry Unit,

Department of Parasitology, Leiden University Medical Center,

Leiden, The Netherlands

H. Miller-Podraza

Institute of Biomedicine,

Department of Medical Chemistry and Cell Biology,

Göteborg University,

Göteborg, Sweden 


$\begin{array}{ll}\text { G } & N \text {-glycolylneuraminic acid } \\ \text { GvHD } & \text { graft versus host disease } \\ \text { H } & \text { hexose } \\ \text { HSA } & \text { Human serum albumin } \\ \text { LacNAc } & N \text {-acetyllactosamine } \\ \text { Lea } & \text { Lewis a } \\ \text { Lex } & \text { Lewis } x \\ \text { MALDI-TOF } & \text { matrix-assisted laser desorption-ionization } \\ & \text { time-of-flight } \\ \text { MS } & \text { mass spectrometry } \\ \text { MSC } & \text { mesenchymal stem cell } \\ \text { MS/MS } & \text { tandem mass spectrometry } \\ \mathrm{N} & \text { N-acetylhexosamine } \\ \text { NMR } & \text { nuclear magnetic resonance } \\ \text { OG } & \text { MSCs differentiated into osteogenic } \\ & \text { direction } \\ \text { P } & \text { phosphate or sulfate } \\ \text { PBS } & \text { phosphate buffered saline } \\ \text { Poly-LacNAc } & \text { poly- } N \text {-acetyllactosamine } \\ \text { S } & N \text {-acetylneuraminic acid } \\ \text { sLex } & \text { sialyl Lewis x } \\ & \end{array}$

\section{Introduction}

Human stem cells possess an enormous potential for future regenerative medicine. However, the clinical use of human pluripotent embryonic stem cells has to overcome numerous ethical and technical barriers. Therefore, the use of adult multipotent stem cells is a noteworthy alternative to fulfill the therapeutic expectations $[1,2]$.

Human mesenchymal stem cells (MSCs) or mesenchymal stromal cells are fibroblast-like adult multipotent progenitor cells that reside in several anatomical locations, for example in bone marrow and in adipose tissue $[3,4]$. The presence of MSCs in blood has been demonstrated in rodents [5] with their major function being the repair of injured tissues [4]. MSCs have also been reportedly isolated from human cord blood $[6,7]$. MSCs have been shown to have the potential to differentiate at least into adipocytes, chondrocytes, osteoblasts, myoblasts and tenocytes in vitro [4].

The therapeutic potential of MSCs is yet to be defined. In vitro and in vivo experimental results are very promising and suggest that MSC therapy can be applied in many acute and subacute conditions to enhance or direct the spontaneous healing process. There are preliminary results of the successful use of MSCs to promote myocardial repair after acute infarction [8] and bone repair [9]. Other implications where MSC therapy has been successful include osteogenesis imperfecta [10] and acute graftversus-host disease (GvHD) [11]. Preliminary clinical data also exist on the treatment of spinal cord injury with MSCs
[12]. All this emerging evidence suggests that cellular therapy is in the process of becoming part of the everyday clinical practice, although the key applications remain to be established.

In order to fulfill the expectations raised by MSCs for stem cell therapy, several biological questions need to be addressed. A specific molecular marker for MSCs to be used in the preparation of pure stem cell populations does not exist. Moreover, there is a need for a validated MSC culture protocol in order to enhance the proliferation of MSCs for either autologous or allogenic transplants, and to produce MSCs free of animal-derived materials and of sufficient purity for therapeutic purposes. Precise and accurate information on the in vivo distribution of MSCs upon transplantation needs to be established in order to obtain the desired transplantation outcome. For all these purposes any additional and novel information about MSC surface structures would be beneficial.

Cell surface structures are generally known to be involved in the interactions between cells as well as in the binding of cells to the extracellular matrix. Of the 3 main cell surface macromolecule classes, proteins as mere polypeptides have previously been assumed to convey the majority of plasma membrane functions, such as acting as receptors, transporters and adhesive molecules. Lipids and glycans have been considered less important for these cellular functions throughout the history of biological science. Only in the last few decades has the functional status of the glycocalyx covering all cell surfaces been fully appreciated, partly through technological developments in glycoscience, and also through genetic and molecular insights into glycoconjugate biosynthesis and recognition. These glycans attached to either membrane proteins or lipids have multiple and diverse roles in biology [13].

Glycobiology has been shown to play an important role in mammalian development [14], starting from fertilization of the oocyte. Further processes of development and differentiation involve many specialized tasks carried out by specific glycans and their receptors [13, 15]. A wellstudied function of polysialic acids in the development of the nervous system can be mentioned as an example [16]. Transgenic animals deficient in glycosyltransferase genes are often used as a model to study the effects of glycosylation during developmental processes [17, 18]. The animal models used in these studies vary from amphibians to mammals, with the mouse being the most widely used model system. Cell surface glycans, however, are known to be very species specific [19]. Therefore, direct conclusions can not be drawn about the correspondence between these animal studies and human developmental processes.

Stem cell glycosylation has been shown to have unique features, as presented in a recent review [20]. Recent 
reports discuss carbohydrate antigens mainly in embryonic [21] and neural [16] stem cells. The majority of the studies performed to date have been carried out by using different glycan binding proteins, e.g. lectins or antibodies against glycan epitopes [22-24]. Of these binders, antibodies against SSEA-3, SSEA-4, Tra-1-60, Tra-1-81 [25, 26] have been generally accepted as tools for embryonic stem cell validation [27]. We have documented the glycan structures in hematopoietic stem cells and further verified glycosyltransferase gene expression profiles that are consistent with observed glycan structures [28].

In this study, we have used mass spectrometric (MS) profiling and nuclear magnetic resonance (NMR) spectroscopy to study the cellular glycome of bone marrow-derived MSCs and osteoblasts derived from them. We have characterized specific glycan structures by specific glycosidase enzymes, mass spectrometric fragmentation analyses and high resolution MS. The cell surface presentation of certain glycan epitopes has been further verified by staining the cells with antibodies and lectins.

\section{Materials and methods}

Cells

Bone marrow-derived MSCs were obtained as described previously [29]. In brief, bone marrow from femoral collum and trochanteric region obtained during orthopedic surgery was cultured in minimum essential $\alpha$-medium ( $\alpha$-MEM), supplemented with $20 \mathrm{mM}$ HEPES, $10 \%$ fetal calf serum, $1 \times$ penicillin-streptomycin, and $2 \mathrm{mM} \mathrm{L}$-glutamine (all from Gibco). After a cell attachment period of 2 days, the cells were washed with $\mathrm{Ca}^{2+}$ and $\mathrm{Mg}^{2+}$-free phosphatebuffered saline (PBS) (Gibco) and subcultured further by plating the cells at a density of 2,000 to $3,000 \mathrm{cells} / \mathrm{cm}^{2}$ in the same medium. Half of the medium was replaced by fresh medium twice a week until confluence was almost reached.

The MSC lines used were analyzed for MSC phenotype as described [30]. The cell lines were analyzed by flow cytometry for the expression of the MSC markers (CD73, CD90 and CD105) and the absence of differentiation markers (CD14, CD19, CD34, CD45 and HLA-DR). Fluorescein isothiocyanate (FITC)- or phycoerythrin-conjugated antibodies against $\mathrm{CD} 14, \mathrm{CD} 34, \mathrm{CD} 45$ and $\mathrm{CD} 73$ were from BD Biosciences (San Jose, CA) and against CD105 from Abcam Ltd. (Cambridge, U.K.). FITC- and phycoerythrinconjugated isotypic controls were from BD Biosciences. Unconjugated antibodies against CD90 and human leukocyte antigens HLA-DR were from BD Biosciences. FITC-conjugated goat anti-mouse IgG antibody was from Sigma-Aldrich.
Five different MSC lines were used for mass spectrometric analyses and 3 of these were used in flow cytometry and cytochemical stainings.

Osteogenic differentiation of mesenchymal stem cells

Induction of the osteogenic differentiation of the bone marrow-derived MSCs was carried out essentially as described [30]. The osteogenic induction medium consisted of $\alpha$-MEM (Gibco) supplemented with $10 \%$ fetal calf serum (Gibco), $20 \mathrm{mM}$ HEPES (Gibco), $0.1 \mu \mathrm{M}$ dexamethasone (Decadron; Merck \& Co., Inc., Whitehouse Station, NJ), $10 \mathrm{mM}$ ß-glycerophosphate, $0.05 \mathrm{mM} \mathrm{L}$ ascorbic acid-2-phosphate (Sigma-Aldrich), and penicillinstreptomycin (Gibco). The cells were cultured for up to 6 weeks, changing the medium twice a week. Osteogenic differentiation was evaluated by alkaline phosphatase activity measurement and von Kossa staining [29].

Glycan binding proteins

Antibodies (Ab) against Lex (clone 28), sialyl Lex (sLex) (KM93), SSEA-3 (MC-631) and SSEA-4 (MC-813-70) were from Chemicon (Millipore; Billerica, MA). FITClabeled lectins, HHA from Hippeastrum hybrid, MAA from Maackia amurensis, PWA from Phytolacca americana and STA from Solanum tuberosum, were from EY Laboratories, Inc. (San Mateo, CA, USA); SNA from Sambucus nigra was from Vector Laboratories (Burlingame, CA, USA).

\section{Glycan isolation}

Cells were prepared for glycan analysis essentially as described [28]. Cells were washed with PBS, scraped, collected with PBS and centrifuged for $5 \mathrm{~min}$ at $400 \times g$. The pellet was washed twice with PBS and finally the cells were collected by centrifugation. The cell pellet was stored at $-70^{\circ} \mathrm{C}$ and used for glycome analysis. Asparagine-linked glycans were detached from cellular glycoproteins by $F$. meningosepticum peptide:N-glycosidase F (PNGase F) digestion (Calbiochem, San Diego). The released asparaginelinked glycans (N-glycans) were purified for analysis by organic extraction-precipitation and miniaturized solid-phase extraction steps as described [28]. Serine- and threoninelinked glycans (O-glycans) were detached from cellular glycoproteins by non-reductive $\beta$-elimination with saturated ammonium carbonate in concentrated ammonia at $60^{\circ} \mathrm{C}$ [31]. Glycosphingolipids were isolated by extraction using organic solvents, phase partition (Folch's phase), and gel filtration/ solid-phase extraction using a Sephadex G-25 (Amersham Pharmacia) column [32]. Glycosphingolipid glycans were detached by Macrobdella decora endoglycoceramidase (Calbiochem) digestion. After isolation, both O-linked 
and sphingolipid-linked oligosaccharides were purified similarly as $\mathrm{N}$-glycans. Recoveries of $\mathrm{N}$-glycans were greater than either O-glycans or glycosphingolipid glycans. For each N-glycan analysis, 300,000 to 500,000 cells were prepared. O-glycans were isolated from the de-N-glycosylated protein samples recovered during the precipitation-extraction purification step [28]. For subsequent $\mathrm{O}$-glycan isolation, multiple glycoprotein samples were pooled. For glycosphingolipid glycan isolation, 6 to 14 million cells were prepared. Aliquots of the glycan fractions were used in each mass spectrometric analysis, corresponding to on average 170,000 cells for N-glycans, over 1 million cells for O-glycans, and on average 2.5 million cells for glycosphingolipid glycans. During glycan purification with size-exclusion HPLC, we observed absorbance peaks at $214 \mathrm{~nm}$ in the N-glycan area for both neutral and acidic N-glycan fractions. Molar amounts of recovered $\mathrm{N}$-glycans were determined against external GlcNAc and Neu5Ac standards at $214 \mathrm{~nm}$ using the most abundant monosaccharide compositions in each fraction for calculation: $\mathrm{GlcNAc}_{2}$ for neutral $\mathrm{N}$-glycans and Neu5 $\mathrm{Ac}_{2} \mathrm{GlcNAc}_{4}$ for acidic N-glycans. The result of the integration was $1 \mathrm{nmol}$ total $\mathrm{N}$-glycans/1 million MSCs. Because the $\mathrm{N}$-glycan fractions contained also larger glycans with more GlcNAc or Neu5Ac residues as determined by mass spectrometry, the result means that actual recovery was less than $1 \mathrm{nmol} / 1$ million cells.

\section{Glycosidase treatments}

Analysis of nonreducing glycan epitopes present in isolated glycan fractions was performed by digestion with specific glycosidase enzymes and subsequent mass spectrometric detection as described [28]. Employed glycosidase enzymes included $\beta 1,4$-galactosidase ( $\beta 4 \mathrm{Gal} ; 0.9 \mathrm{mU} /$ reaction, to digest LacNAc but neither Gal $\beta 1-3$ GlcNAc nor Gal $\alpha 1$ 3LacNAc) from Streptococcus pneumoniae (recombinant in Escherichia coli; Calbiochem), $\beta 1,3$-galactosidase ( $\beta 3 \mathrm{Gal} ; 2.3 \mathrm{mU} /$ reaction, to digest $\mathrm{Gal} \beta 1-3 \mathrm{GlcNAc}$ ) from Xanthomonas manihotis (recombinant in E. coli; Calbiochem), $\alpha 2,3$-sialidase ( $\alpha 3 \mathrm{SA} ; 3.5 \mathrm{mU} /$ reaction, to digest Neu5Ac $\alpha 2-3 \mathrm{LacNAc}$ but not Neu5Ac $\alpha 2-6 \mathrm{LacNAc}$ ) from $S$. pneumoniae (recombinant in E. coli; Glyko/ProZyme, San Leandro, CA, USA), broad-range sialidase (SA; $1.5 \mathrm{mU} /$ reaction, to digest Neu5Ac $\alpha 2-3 \mathrm{Gal}$ and Neu5Ac $\alpha 2-6 \mathrm{Gal}$ ) from Arthrobacter ureafaciens (recombinant in E. coli; Calbiochem), $\alpha 1,3 / 4$-fucosidase ( $\alpha 3 / 4 \mathrm{Fuc} ; 0.1 \mathrm{mU} /$ reaction, to digest Fuc $\alpha 1-3($ Gal $\beta 1-4)$ GlcNAc but not Fuc $\alpha 1-2$ Gal $\beta 1$ 3GlcNAc) from Xanthomonas sp. (Calbiochem), $\alpha 1,2-$ fucosidase ( $\alpha 2$ Fuc; $0,15 \mathrm{mU} /$ reaction to digest Fuc $\alpha 1-2 \mathrm{Gal}$ but not Fuc $\alpha 1-3$ GlcNAc or Fuc $\alpha 1-4 \mathrm{GlcNAc}$ ) from Xanthomonas manihotis (Glyko/ProZyme), $\alpha$-mannosidase ( $\alpha$ Man; $50 \mathrm{mU} /$ reaction, to digest the high-mannose type $\mathrm{N}$-glycans) from Jack beans (Canavalia ensiformis; Sigma-Aldrich), endo- $\beta$-galactosidase $(2.5 \mathrm{mU} /$ reaction, to digest polylactosamines) from Escherichia freundii (Seikagaku Corp., Tokyo, Japan) and $\beta$ - $N$-acetylglucosaminidase $(\beta \mathrm{GN}$; $9.4 \mathrm{mU} /$ reaction, to digest GlcNAc $\beta 1-3 \mathrm{LacNAc}$ but not GalNAc $\beta 1-4 \mathrm{GlcNAc}$ ) from $S$. pneumoniae (recombinant in E. coli, Calbiochem). Reactions with approximately 1$10 \mathrm{pmol}$ of oligosaccharides were carried out by overnight digestion at $+37^{\circ} \mathrm{C}$ in $10 \mu \mathrm{L}$ of $50 \mathrm{mM}$ sodium acetate buffer $\mathrm{pH}$ 5.5.Digested glycan fractions were purified for analysis by solid-phase extraction with graphitized carbon as described above.

\section{Mass spectrometry}

Matrix-assisted laser desorption-ionization time-of-light (MALDI-TOF) MS was performed with a Bruker Ultraflex TOF/TOF instrument (Bruker Daltonics Inc, Bremen, Germany). Neutral glycans were detected in positive ion reflector mode as $[\mathrm{M}+\mathrm{Na}]+$ ions and acidic glycans were detected in negative ion reflector mode as $[\mathrm{M}-\mathrm{H}]$-ions. Relative intensities of identified glycan signals were calculated separately for neutral and acidic glycan profiles. Signal intensities were determined using Flexanalysis 3.0 software (Bruker Daltonics). The present glycan profiles were extracted from the resulting signal lists by removing the effect of isotopic pattern overlapping, multiple alkali metal adduct signals, products of elimination of water from the reducing oligosaccharides, contaminating signals from endoglycoceramidase enzyme preparation and other interfering mass spectrometric signals not arising from the glycan components in the sample. The resulting glycan signal intensities in overall profiles were summarized to be $100 \%$ in order to allow comparison between samples as described [28, 33].

For mass spectrometric fragmentation analysis, glycans were permethylated by a solid-phase microcolumn technique [34]. Mass spectrometric fragmentation of permethylated glycans was performed using the Bruker Ultraflex TOF/ TOF instrument according to manufacturer's instructions.

High resolution and mass accuracy analyses were achieved by matrix-assisted laser desorption/ionization Fourier transform ion cyclotron mass spectrometry (MALDI-FT-ICR-MS; 9.4 T ApexUltra equipped with a combisource; Bruker Daltonics) using 2,5-dihydroxybenzoic acid $(20 \mathrm{mg} / \mathrm{mL}$ in $30 \%$ acetonitrile) as a matrix. A set of 4 assigned sialylated $\mathrm{N}$-glycans were used for internal calibration.

Nuclear magnetic resonance spectroscopy

The isolated glycans were purified for ${ }^{1} \mathrm{H}$ NMR spectroscopy by gel filtration chromatography [28]. Prior to NMR experiments the saccharides were dissolved in $\mathrm{D}_{2} \mathrm{O}$ and 
evaporated to dryness. The samples were then dissolved in $280 \mu \mathrm{L}$ of $\mathrm{D}_{2} \mathrm{O}$ (99.996 atom \%; Cambridge Isotope Laboratories) in Shigemi NMR tubes (Shigemi Co., LTD). The experiments were carried out on a Varian Unity INOVA $600 \mathrm{MHz}$ spectrometer equipped with a cryoprobe for enhanced sensitivity. All spectra were measured at $23^{\circ} \mathrm{C}$. In recording one-dimensional ${ }^{1} \mathrm{H}$ spectra presaturation was used for water suppression.

Immunocytochemistry and lectin staining

FITC-labeled lectin and anti-carbohydrate $\mathrm{Ab}$ binding was used to study the cell surface carbohydrate expression. Cells grown on 8 -well chamber slides were fixed with $4 \%$ paraformaldehyde at RT for 10-15 min and washed with PBS. FITC-labeled lectin in dilution of $5-40 \mu \mathrm{g} / \mathrm{mL}$ in $1 \%$ human serum albumin (HSA)-PBS (Finnish Red Cross Blood Service, Finland) was incubated at RT for $60 \mathrm{~min}$. For $\mathrm{Ab}$ stainings non-specific binding sites were blocked with 3\% HSA-PBS for $30 \mathrm{~min}$ at RT. Primary Abs were diluted in 1\% HSA-PBS (1:10-1:200) and incubated for $60 \mathrm{~min}$ at room temperature (RT), followed by washings 3 times with PBS. Secondary Abs were diluted in 1\% HSAPBS and incubated for $60 \mathrm{~min}$ at RT in the dark. Staining with secondary $\mathrm{Ab}$ alone was carried out as a control for each experiment. Cells were washed 3 times with PBS and mounted in Vectashield mounting medium containing DAPI-stain (Vector Laboratories, UK). Stainings were observed with Zeiss Axioskop 2 plus-fluorescence microscope (Carl Zeiss Vision GmbH, Germany) with FITC and DAPI filters. Images were taken with Zeiss AxioCam MRccamera and with AxioVision Software 3.1/4.0 (Carl Zeiss).

\section{Flow cytometry}

Cells were washed with PBS and harvested into single cell suspensions by $0.25 \%$ trypsin $/ 1 \mathrm{mM}$ EDTA solution (Gibco). Detached cells were centrifuged at $300 \times g$ for 5 min at RT. Cell pellet was washed twice with $1 \%$ BSAPBS (ultrapure BSA, Sigma), centrifuged at $600 \times g$ and resuspended in $1 \%$ BSA-PBS. Cells were placed in conical tubes in aliquots of 70,000 to 83,000 cells each. Cell aliquots were incubated with one of the FITC-labeled lectin for $20 \mathrm{~min}$ at room temperature. Lectins were used in dilution of $5 \mu \mathrm{g} / 10^{5}$ cells in $1 \%$ BSA-PBS. Primary Abs were incubated $(4 \mu \mathrm{L} / 100 \mu \mathrm{L}$ cell suspension/50,000 cells) for $30 \mathrm{~min}$ at RT and washed once with $0.3 \%$ BSA-PBS before secondary antibody detection with Alexa Fluor 488 goat anti-mouse (1:500) for $30 \mathrm{~min}$ at RT in the dark. As a negative control, cells were incubated without primary $\mathrm{Ab}$ and otherwise treated similar to labeled cells. After incubation cells were washed with $1 \%$ BSA-PBS, centrifuged and resuspended in $1 \%$ BSA-PBS. Binding was detected by flow cytometry (FACSAria, Becton Dickinson) and fluorescence was measured using 530/30 nm and 575/ $25 \mathrm{~nm}$ bandpass filters. Data analysis was made with BD FACSDiva $^{\mathrm{TM}}$ Flow Cytometry Software Version 5.0.2.

\section{Results}

Profile of the mesenchymal stem cell glycome

To study the overall glycome of MSCs, bone marrowderived cells were either cultured in proliferative state or differentiated into osteogenic direction. $\mathrm{N}$-glycans were released enzymatically from cell lysates by peptide: Nglycosidase F (PNGase F) digestion, O-glycans chemically by non-reductive $\beta$-elimination, and glycosphingolipid glycans enzymatically by endoglycoceramidase digestion. Mass spectrometric profiling of purified MSC N-glycans (Fig. 1a,b) showed 253 different signals, of which 50 major neutral and 50 major acidic signals are listed in Table 1 as well as visualized in Fig. 1c-f. Known polyhexose contaminations [28], marked with asterisks, were discarded from the derived diagrams. The O-glycan profile of bone marrow-derived MSCs revealed 42 different signals. Of these, 10 major acidic signals are listed in Table 1, and the most abundant neutral signal is visualized in Fig. 3. In the lipid glycan profile, 63 signals were observed and 15 major acidic and 20 major neutral signals are listed in Table 1.

Using a mass matching approach, monosaccharide compositions could be proposed for the different glycan signals (Table 1) and annotated in stem cell glycome profiles (Fig. 1e,f). The relative intensities for all the detected glycan signals have been calculated. The relative intensity of a single peak is expressed as percentages of total glycan profile, which has been given a value of $100 \%$. We and others have documented that the percentages determined in this way are useful for relative quantitative comparison of glycan profile changes [28, 33]. The mean values of 5 different biological replicates are shown. The glycan profiles were highly similar in the 5 different MSC lines analyzed, as can be determined from the small deviations within the observed glycan profiles (Fig. 1c,d). The small profile differences between the 5 biological replicates, also observed for the lineage-committed cells, indicates that MSCs have a very characteristic N-glycome and that the glycome change during osteogenic differentiation occurs in a predetermined fashion.

$\mathrm{N}$-glycans were grouped according to composition calculation into different glycan classes, e.g. mannosetype, complex-type and hybrid-type structures (Fig. 1e,f). Mannose-type N-glycans dominated in the neutral N-glycan profile comprising $78 \%$ of MSC signals and $58 \%$ of osteoblast signals. Complex-type N-glycans comprised $12 \%$ of 

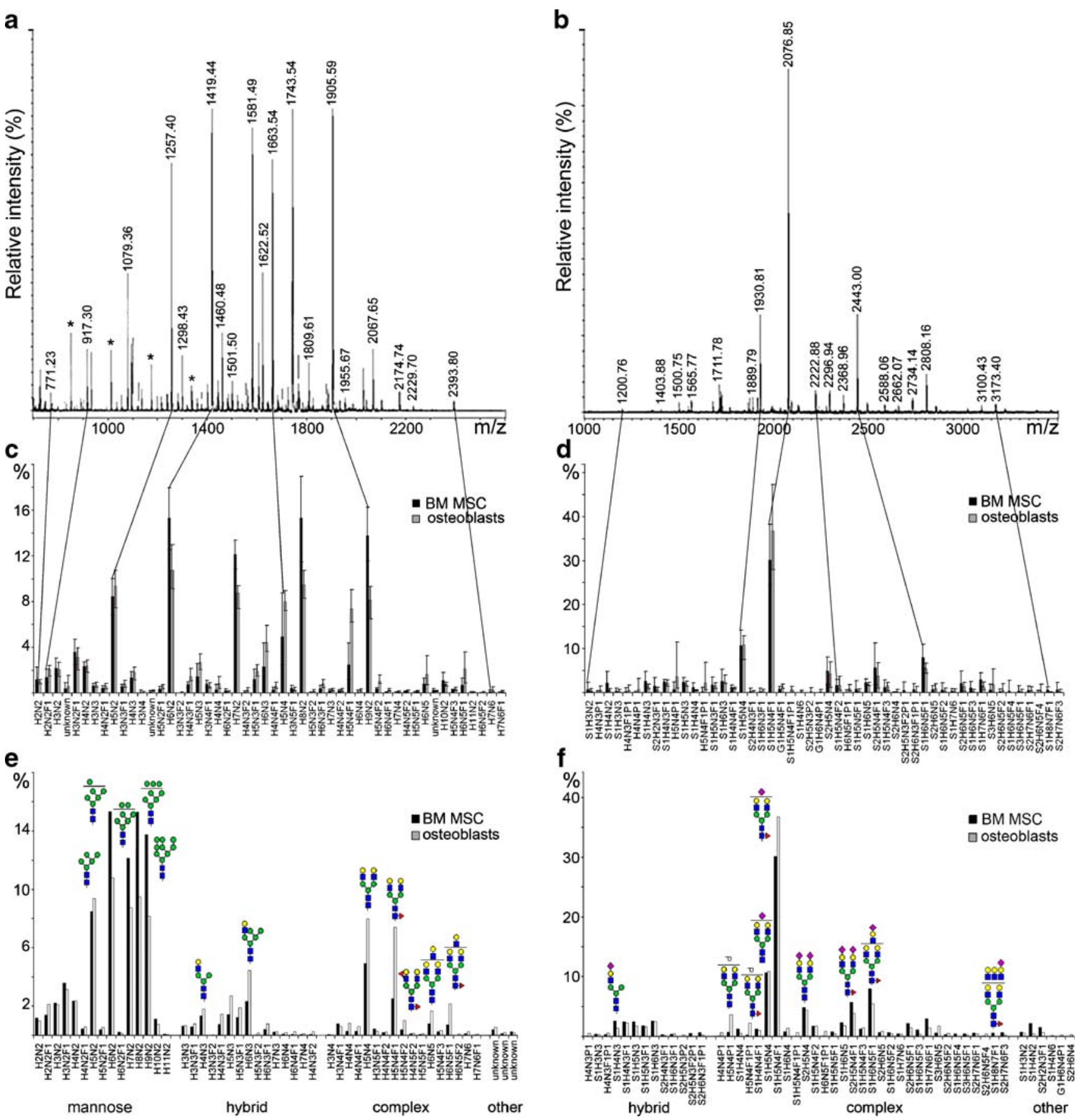

Fig 1 Mass spectrometric N-glycome profile of MSCs. Mass spectra of neutral (a) and acidic (b) N-glycans from bone marrow (BM)derived MCSs are shown. Fifty major glycan peaks from five studied MSC lines (black bars) as well as their osteoblast counterparts (grey bars) are derived from mass spectrometric data (lines from a to $\mathbf{c}$ and b to d) and visualized according to their relative intensities (c neutral $\mathrm{N}$-glycans; $\mathbf{d}$ acidic $\mathrm{N}$-glycans). In panel $\mathbf{e}$, neutral $\mathrm{N}$-glycans and in

MSC signals and $25 \%$ of osteoblast signals, while only $9 \%$ of MSC signals and $16 \%$ of osteoblast signals were determined as hybrid-type. In the acidic $\mathrm{N}$-glycan fraction, complex-type $\mathrm{N}$-glycans comprised the majority of the total glycan profile, panel $\mathbf{f}$ acidic $\mathrm{N}$-glycans are grouped according to their structural classes. Glycan species are annotated with proposed structures derived by mass calculation. Blue square represents $N$-acetylglucosamine, green circle mannose, yellow circle galactose, red triangle fucose, pink diamond $N$-acetylneuraminic acid and $P$ either sulfate or phosphate. Known polyhexose contaminations are marked with asterisks

$80 \%$ in MSCs and $86 \%$ in osteoblasts. Hybrid-type and monoantennary $\mathrm{N}$-glycans were less abundant. There were few signals that could not be assigned to glycan structures by mass matching approach. 
Table 1 Major mass spectrometric glycan signals of mesenchymal stem cells (MSC) and their osteogenic counterparts (OG)

\begin{tabular}{|c|c|c|c|c|c|c|c|c|c|c|c|}
\hline \multicolumn{4}{|c|}{ Neutral N-glycans } & \multicolumn{4}{|c|}{ Acidic N-glycans } & \multicolumn{4}{|c|}{ Neutral lipid glycans } \\
\hline $\mathrm{m} / \mathrm{z}$ & Composition & $\begin{array}{l}\% \text { in } \\
\text { MSC }\end{array}$ & $\begin{array}{l}\% \text { in } \\
\text { OG }\end{array}$ & $\mathrm{m} / \mathrm{z}$ & Composition & $\begin{array}{l}\% \text { in } \\
\text { MSC }\end{array}$ & $\begin{array}{l}\% \text { in } \\
\text { OG }\end{array}$ & $\mathrm{m} / \mathrm{z}$ & Composition & $\begin{array}{l}\% \text { in } \\
\text { MSC }\end{array}$ & $\begin{array}{l}\% \text { in } \\
\text { OG }\end{array}$ \\
\hline 771.26 & $\mathrm{H} 2 \mathrm{~N} 2$ & 1.1 & 1.0 & $1,200.42$ & S1H3N2 & 0.8 & 0.6 & 527.16 & $\mathrm{H} 3$ & 22.3 & 9.1 \\
\hline 917.32 & $\mathrm{H} 2 \mathrm{~N} 2 \mathrm{~F} 1$ & 1.4 & 2.1 & $1,354.41$ & H4N3P1 & 0.1 & 0.6 & 568.19 & $\mathrm{H} 2 \mathrm{~N} 1$ & 17.3 & 13.3 \\
\hline 933.31 & $\mathrm{H} 3 \mathrm{~N} 2$ & 2.1 & 2.1 & $1,362.47$ & $\mathrm{~S} 1 \mathrm{H} 4 \mathrm{~N} 2$ & 2.2 & 0.5 & 609.21 & H1N2 & 0.0 & 1.1 \\
\hline $1,031.33$ & unknown & 0.3 & 0.6 & $1,403.49$ & $\mathrm{~S} 1 \mathrm{H} 3 \mathrm{~N} 3$ & 0.4 & 0.3 & 730.24 & H3N1 & 22.5 & 25.2 \\
\hline $1,079.38$ & $\mathrm{H} 3 \mathrm{~N} 2 \mathrm{~F} 1$ & 3.6 & 3.2 & $1,500.47$ & H4N3F1P1 & 0.3 & 0.7 & 755.27 & H1N2F1 & 0.9 & 0.0 \\
\hline $1,095.37$ & H4N2 & 2.3 & 2.3 & $1,557.48$ & H4N4P1 & 0.0 & 0.8 & 771.26 & $\mathrm{H} 2 \mathrm{~N} 2$ & 15.4 & 24.8 \\
\hline $1,136.40$ & H3N3 & 0.7 & 0.7 & $1,565.55$ & $\mathrm{~S} 1 \mathrm{H} 4 \mathrm{~N} 3$ & 2.7 & 1.4 & 892.29 & H4N1 & 0.0 & 0.9 \\
\hline $1,241.43$ & $\mathrm{H} 4 \mathrm{~N} 2 \mathrm{~F} 1$ & 0.4 & 0.6 & $1,678.60$ & $\mathrm{~S} 2 \mathrm{H} 2 \mathrm{~N} 3 \mathrm{~F} 1$ & 1.6 & 0.7 & 933.32 & H3N2 & 9.0 & 12.8 \\
\hline $1,257.42$ & H5N2 & 8.5 & 9.1 & $1,711.61$ & S1H4N3F1 & 2.5 & 2.3 & 974.34 & $\mathrm{H} 2 \mathrm{~N} 3$ & 0.3 & 0.0 \\
\hline $1,282.45$ & H3N3F1 & 0.6 & 0.8 & $1,719.54$ & H5N4P1 & 0.8 & 4.1 & $1,031.00$ & unknown & 0.3 & 0.8 \\
\hline $1,298.45$ & H4N3 & 1.3 & 1.9 & $1,727.60$ & S1H5N3 & 2.5 & 1.8 & $1,038.35$ & H4N1F1 & 0.0 & 0.4 \\
\hline $1,339.48$ & H3N4 & 0.1 & 0.1 & $1,768.57$ & S1H4N4 & 1.3 & 0.5 & $1,079.38$ & H3N2F1 & 0.2 & 0.4 \\
\hline $1,393.00$ & unknown & 0.1 & 0.2 & $1,865.60$ & H5N4F1P1 & 0.3 & 2.6 & $1,095.37$ & H4N2 & 4.2 & 5.7 \\
\hline $1,403.48$ & H5N2F1 & 0.4 & 0.5 & $1,873.66$ & S1H5N3F1 & 2.0 & 1.5 & $1,136.40$ & $\mathrm{H} 3 \mathrm{~N} 3$ & 2.2 & 2.2 \\
\hline $1,419.48$ & H6N2 & 15.4 & 10.5 & $1,889.65$ & S1H6N3 & 2.7 & 2.5 & $1,241.43$ & H4N2F1 & 0.2 & 0.4 \\
\hline $1,428.51$ & $\mathrm{H} 3 \mathrm{~N} 3 \mathrm{~F} 2$ & 0.0 & 0.0 & $1,914.68$ & S1H4N4F1 & 1.3 & 1.0 & $1,298.45$ & H4N3 & 1.2 & 1.1 \\
\hline $1,444.51$ & H4N3F1 & 0.8 & 1.5 & $1,930.68$ & S1H5N4 & 11.2 & 11.0 & $1,339.48$ & H3N4 & 0.3 & 0.1 \\
\hline $1,460.50$ & H5N3 & 1.5 & 2.8 & $2,002.70$ & S2H4N3F1 & 0.3 & 0.2 & $1,419.48$ & H6N2 & 0.7 & 0.4 \\
\hline $1,485.53$ & H3N4F1 & 0.8 & 0.6 & $2,035.71$ & S1H6N3F1 & 0.4 & 0.4 & $1,460.50$ & H5N3 & 0.6 & 0.4 \\
\hline $1,501.53$ & H4N4 & 0.3 & 0.9 & $2,076.74$ & S1H5N4F1 & 31.0 & 36.4 & $1,501.53$ & H4N4 & 0.4 & 0.0 \\
\hline $1,565.53$ & H6N2F1 & 0.2 & 0.1 & $2,092.73$ & S1H6N4 & 0.8 & 1.3 & $1,743.58$ & H8N2 & 0.2 & 0.1 \\
\hline $1,581.53$ & H7N2 & 12.1 & 8.7 & $2,156.74$ & S1H5N4F1P1 & 0.0 & 0.6 & $1,784.61$ & H7N3 & 0.2 & 0.2 \\
\hline $1,590.57$ & $\mathrm{H} 4 \mathrm{~N} 3 \mathrm{~F} 2$ & 0.1 & 0.3 & $2,174.79$ & S1H4N6 & 0.0 & 0.1 & $1,882.68$ & H4N3F4 & 0.1 & 0.2 \\
\hline $1,606.56$ & $\mathrm{H} 5 \mathrm{~N} 3 \mathrm{~F} 1$ & 1.2 & 1.9 & $2,178.61$ & $\mathrm{~S} 2 \mathrm{H} 5 \mathrm{~N} 3 \mathrm{P} 2$ & 0.0 & 0.1 & \multicolumn{4}{|c|}{ Acidic Lipid Glycans } \\
\hline $1,622.56$ & H6N3 & 2.4 & 4.5 & $2,188.76$ & G1H6N4P1 & 0.0 & 0.2 & 632.20 & $\mathrm{~S} 1 \mathrm{H} 2$ & 32.1 & 26.1 \\
\hline $1,647.59$ & H4N4F1 & 0.3 & 0.6 & $2,221.78$ & S2H5N4 & 4.4 & 4.0 & 923.30 & $\mathrm{~S} 2 \mathrm{H} 2$ & 17.3 & 10.2 \\
\hline $1,663.58$ & $\mathrm{H} 5 \mathrm{~N} 4$ & 5.0 & 8.1 & $2,222.80$ & S1H5N4F2 & 1.8 & 1.7 & 997.34 & S1H3N1 & 11.4 & 25.3 \\
\hline $1,688.61$ & H3N5F1 & 0.4 & 0.3 & $2,230.73$ & H6N5F1P1 & 0.1 & 0.9 & $1,126.38$ & $\mathrm{~S} 2 \mathrm{H} 2 \mathrm{~N} 1$ & 0.0 & 2.2 \\
\hline $1,743.58$ & H8N2 & 15.3 & 9.4 & $2,279.82$ & S1H5N5F1 & 0.7 & 0.4 & $1,184.42$ & S1H2N2F1 & 3.9 & 6.5 \\
\hline $1,752.62$ & $\mathrm{H} 5 \mathrm{~N} 3 \mathrm{~F} 2$ & 0.0 & 0.2 & $2,295.81$ & S1H6N5 & 2.3 & 1.8 & $1,200.42$ & $\mathrm{~S} 1 \mathrm{H} 3 \mathrm{~N} 2$ & 4.9 & 0.0 \\
\hline $1,768.61$ & H6N3F1 & 0.4 & 0.8 & $2,367.83$ & S2H5N4F1 & 5.0 & 3.4 & $1,216.41$ & G1H3N2 & 1.1 & 0.0 \\
\hline $1,784.61$ & H7N3 & 0.2 & 0.3 & $2,368.85$ & S1H5N4F3 & 1.0 & 1.4 & $1,362.47$ & $\mathrm{~S} 1 \mathrm{H} 3$ & 8.4 & 13.6 \\
\hline $1,793.64$ & H4N4F2 & 0.2 & 0.2 & $2,383.83$ & S2H6N4 & 0.0 & 0.2 & $1,403.49$ & S1H3N3 & 2.8 & 2.1 \\
\hline $1,809.64$ & H5N4F1 & 2.4 & 7.5 & $2,390.77$ & $\mathrm{~S} 2 \mathrm{H} 5 \mathrm{~N} 3 \mathrm{~F} 2 \mathrm{P} 1$ & 0.5 & 0.0 & $1,565.55$ & $\mathrm{~S} 1 \mathrm{H} 4 \mathrm{~N} 3$ & 4.4 & 0.0 \\
\hline $1,825.63$ & H6N4 & 0.1 & 0.3 & $2,406.76$ & S2H6N3F1P1 & 0.6 & 0.3 & $1,606.56$ & S1H3N4 & 1.5 & 0.0 \\
\hline $1,905.63$ & H9N2 & 13.8 & 8.0 & $2,441.87$ & S1H6N5F1 & 8.1 & 5.3 & $1,727.60$ & S1H5N3 & 1.4 & 2.0 \\
\hline $1,955.70$ & H5N4F2 & 0.4 & 1.1 & $2,586.91$ & S2H6N5 & 0.7 & 0.8 & $1,768.63$ & S1H4N4 & 2.0 & 0.0 \\
\hline $1,971.69$ & H6N4F1 & 0.1 & 0.3 & $2,587.93$ & S1H6N5F2 & 0.5 & 0.4 & $1,889.65$ & S1H6N3 & 1.7 & 0.0 \\
\hline $1,987.69$ & H7N4 & 0.0 & 0.1 & $2,660.94$ & S1H7N6 & 0.4 & 0.4 & $2,019.72$ & S1H5N3F2 & 3.7 & 3.7 \\
\hline $1,996.72$ & $\mathrm{H} 4 \mathrm{~N} 5 \mathrm{~F} 2$ & 0.1 & 0.1 & $2,732.97$ & S2H6N5F1 & 1.8 & 1.3 & \multicolumn{4}{|c|}{ Acidic O-glycans } \\
\hline $2,012.72$ & $\mathrm{H} 5 \mathrm{~N} 5 \mathrm{~F} 1$ & 0.1 & 0.1 & $2,733.99$ & S1H6N5F3 & 1.0 & 0.4 & 827.22 & $\mathrm{H} 2 \mathrm{~N} 2 \mathrm{P} 1$ & 32.4 & 24.8 \\
\hline $2,028.71$ & H6N5 & 0.8 & 1.7 & $2,807.00$ & S1H7N6F1 & 3.0 & 1.3 & 964.33 & S2H1N1 & 4.0 & 9.5 \\
\hline $2,041.00$ & unknown & 0.2 & 0.2 & $2,878.00$ & S3H6N5 & 0.5 & 1.8 & 973.28 & $\mathrm{H} 2 \mathrm{~N} 2 \mathrm{~F} 1 \mathrm{P} 1$ & 1.6 & 2.0 \\
\hline $2,067.69$ & H10N2 & 1.1 & 0.8 & $2,879.02$ & S2H6N5F2 & 0.2 & 0.6 & $1,038.36$ & S1H2N2 & 19.3 & 39.7 \\
\hline $2,101.76$ & $\mathrm{H} 5 \mathrm{~N} 4 \mathrm{~F} 3$ & 0.3 & 0.3 & $2,880.04$ & S1H6N5F4 & 0.2 & 0.0 & $1,118.32$ & $\mathrm{~S} 1 \mathrm{H} 2 \mathrm{~N} 2 \mathrm{P} 1$ & 2.2 & 5.6 \\
\hline $2,174.77$ & H6N5F1 & 0.7 & 2.2 & $3,024.06$ & S3H6N5F1 & 0.3 & 0.2 & $1,329.46$ & $\mathrm{~S} 2 \mathrm{H} 2 \mathrm{~N} 2$ & 9.4 & 16.7 \\
\hline $2,229.74$ & H11N2 & 0.1 & 0.1 & $3,098.10$ & S2H7N6F1 & 0.5 & 0.4 & $1,403.49$ & $\mathrm{~S} 1 \mathrm{H} 3 \mathrm{~N} 3$ & 2.0 & 0.0 \\
\hline $2,320.83$ & H6N5F2 & 0.0 & 0.1 & $3,171.14$ & S2H6N5F4 & 0.1 & 0.4 & $1,475.44$ & $\mathrm{~S} 2 \mathrm{H} 2 \mathrm{~N} 2 \mathrm{~F} 1$ & 6.6 & 0.3 \\
\hline $2,393.85$ & H7N6 & 0.1 & 0.2 & $3,172.13$ & S1H8N7F1 & 0.6 & 0.0 & $1,637.45$ & $\mathrm{~S} 2 \mathrm{H} 3 \mathrm{~N} 2 \mathrm{~F} 1$ & 4.8 & 1.20 \\
\hline $2,539.90$ & H7N6F1 & 0.0 & 0.1 & $3,390.21$ & S2H7N6F3 & 0.4 & 0.2 & $1,678.51$ & $\mathrm{~S} 2 \mathrm{H} 2 \mathrm{~N} 3 \mathrm{~F} 1$ & 3.2 & 0.0 \\
\hline
\end{tabular}

Proposed compositions are calculated on basis of mass matching approach and annotated as follows: $H$ hexose, $N N$-acetylhexosamine, $F$ deoxyhexose, $S N$-acetylneuraminic acid, $G N$-glycolylneuraminic acid, $P$ sulfate or phosphate 
The N-glycan profiles of bone marrow-derived MSCs and their osteogenic counterparts showed clear characteristic differences (Fig. 1). While high-mannose structures were more dominant in stem cells, complex-type N-glycans lacking $N$-acetylneuraminic acids (S) and neutral hybridtype $\mathrm{N}$-glycans were enriched in cells differentiated into osteogenic direction. High-mannose type N-glycans containing more than 6 hexoses $(\mathrm{H})$ were enriched in MSCs. In differentiated cells, smaller mannose-type $\mathrm{N}$-glycans were relatively more abundant (Fig. 1e). In the acidic N-glycan fraction (Fig. 1f), a characteristic feature of the differentiated cells was the abundance of sulfate or phosphate ester modifications (P) in both complex-type and hybrid-type $\mathrm{N}$-glycans. In stem cells, the acidic $\mathrm{N}$-glycan profile contained relatively more glycans with 2 or more deoxyhexose $(\mathrm{F})$ residues and larger $\mathrm{N}$-glycans with 5 or more $\mathrm{N}$-acetylhexosamine $(\mathrm{N})$ residues. Trace amounts of structures containing $\mathrm{N}$-glycolylneuraminic acid (G) were also detected, including the acidic glycosphingolipid glycan signal G1H3N2 (Table 1). These can be considered markers of cells cultured in the presence of animal-derived materials, as reported both for embryonic stem cells [35] and MSCs [30]. N-glycan signals including G1H5N4 that have been reported earlier [30] were detected, but they were not among the listed 50 most abundant acidic N-glycan signals. The observed xenoantigen contamination is most likely originated from animal-derived components in the cell culture media used.

The mass spectrometric profile of MSC N-glycans was supported by ${ }^{1} \mathrm{H}$ NMR profile of the same structures. Neutral and acidic N-glycan pools were again analyzed separately and the observed spectra were analyzed based on reference data [36-38]. As expected, the detected structures were among the most abundant glycan signals observed by the MS approach. The major signals in the neutral N-glycan pool corresponded to high-mannose type N-glycan structures and they could be annotated as glycans with compositions H7N2, H8N2, and H9N2. In the sialylated $\mathrm{N}$-glycan pool biantennary complex-type $\mathrm{N}$-glycans with type $2 \mathrm{~N}$-acetyllactosamine (LacNAc) antennae were detected. Some of the antennae appeared to be nonsialylated and a some of the detected signals were consistent with core $\alpha 1-6$-linked fucose. Both $\alpha 2-6-$ and $\alpha 2-3$-linked sialic acids were detected, and quantitation of the corresponding signals showed that the predominant linkage was $\alpha 2-3$. The observed signals could be annotated as glycans with compositions S1H5N4, S1H5N4F1, S2H5N4, and S2H5N4F1.

In O-glycan mass spectrometric profiling, both Core-1 sized, with proposed H1N1 core composition, and larger acidic O-glycans, mainly $\mathrm{H} 2 \mathrm{~N} 2$ as core composition, were detected (Table 1). A striking feature in both cell types was the abundance of O-glycans containing sulfate or phosphate ester modifications. Significantly less neutral O-glycans were detected and the recovered neutral O-glycan fraction was contaminated by residual $\mathrm{N}$-glycans. Therefore, only 1 neutral O-glycan could be reliably analyzed with the proposed composition of H2N2 (Fig. 3). The major difference between the O-glycan profiles of stem cells and lineage-committed cells was observed in fucosylated acidic structures, which were markedly enriched in MSCs (Table 1).

In glycosphingolipid profiling, isolated glycans were observed in both neutral and acidic fractions (Table 1). The proposed compositions indicated the presence of ganglioseries (e.g. $\mathrm{S} 2 \mathrm{H} 2$ structure), globo-series (e.g. H4N1 structure), and lacto/neolacto-series glycosphingolipids (e.g. $\mathrm{S} 1 \mathrm{H} 4 \mathrm{~N} 2$ structure) in both MSCs and differentiated cells. One of the main differences detected between the MSCs and the differentiated cells was that the MCSs expressed more small ganglio-type glycans $\mathrm{S} 1 \mathrm{H} 2$ and $\mathrm{S} 2 \mathrm{H} 2$, whereas differentiation was accompanied by an increased expression of larger glycans, such as S1H3N1.

The performed mass spectrometric profiling experiments did not give direct information about the absolute quantities of analytes in the 6 separately analyzed glycan fractions. However, further information about the relative proportions of the fractions could be obtained in separate experiments. The ratio between neutral and acidic Nglycans was determined by treating acidic glycan fractions with sialidase, thus converting them into neutral structures. Digestion products were further analyzed together with neutral N-glycans, and proportions of derived glycans were determined. The molar amount of neutral N-glycans was found to equal approximately twice the molar amount of acidic N-glycans (data not shown). In order to estimate the relative proportions of different glycan classes, only simple conclusions can be drawn. We were repeatedly able to recover and analyze significantly more $\mathrm{N}$-glycans than either lipid- or O-linked glycans from all the cell types studied.

Verification of identified stem cell glycan structures

In addition to MS and NMR profiling, further structural information was needed for the assignment of precise glycan structures. Enzymatic digestions with specific glycosidases were performed in order to verify either specific bonds between monosaccharides or specific monosaccharide locations, of which fucose is shown as an example in Fig. 2a. Here, $\alpha 1,3 / 4$-fucosidase digestion is shown to remove 2 mass spectrometric signals from the neutral N-glycan spectra of bone marrow derived MSCs. These signals correspond to multiply fucosylated structures and their disappearance from the MS spectra indicates either Lea or Lex terminal structures in MSC N-glycans. The same signals were not sensitive to $\alpha 1,2$-fucosidase 
Fig 2 Glycan structure verification by exoglycosidase digestion, mass spectrometric fragmentation of permethylated glycans and high resolution MS. $\alpha 3 / 4$-fucosidase digestion is shown (a) to remove annotated glycan signals of MSC

$\mathrm{N}$-glycans. MS/MS fragmentation is shown to verify a glycosphingolipid glycan structure (b). MALDI-FTICR MS analysis provides evidence for 5 sulfated, but not phosphated glycan species (c). Glycan annotations are as in Fig. 1

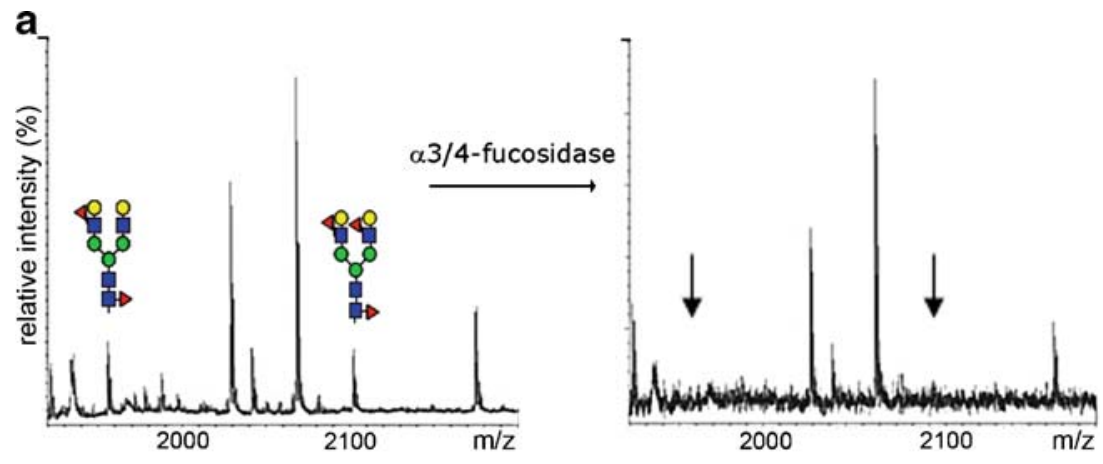

b
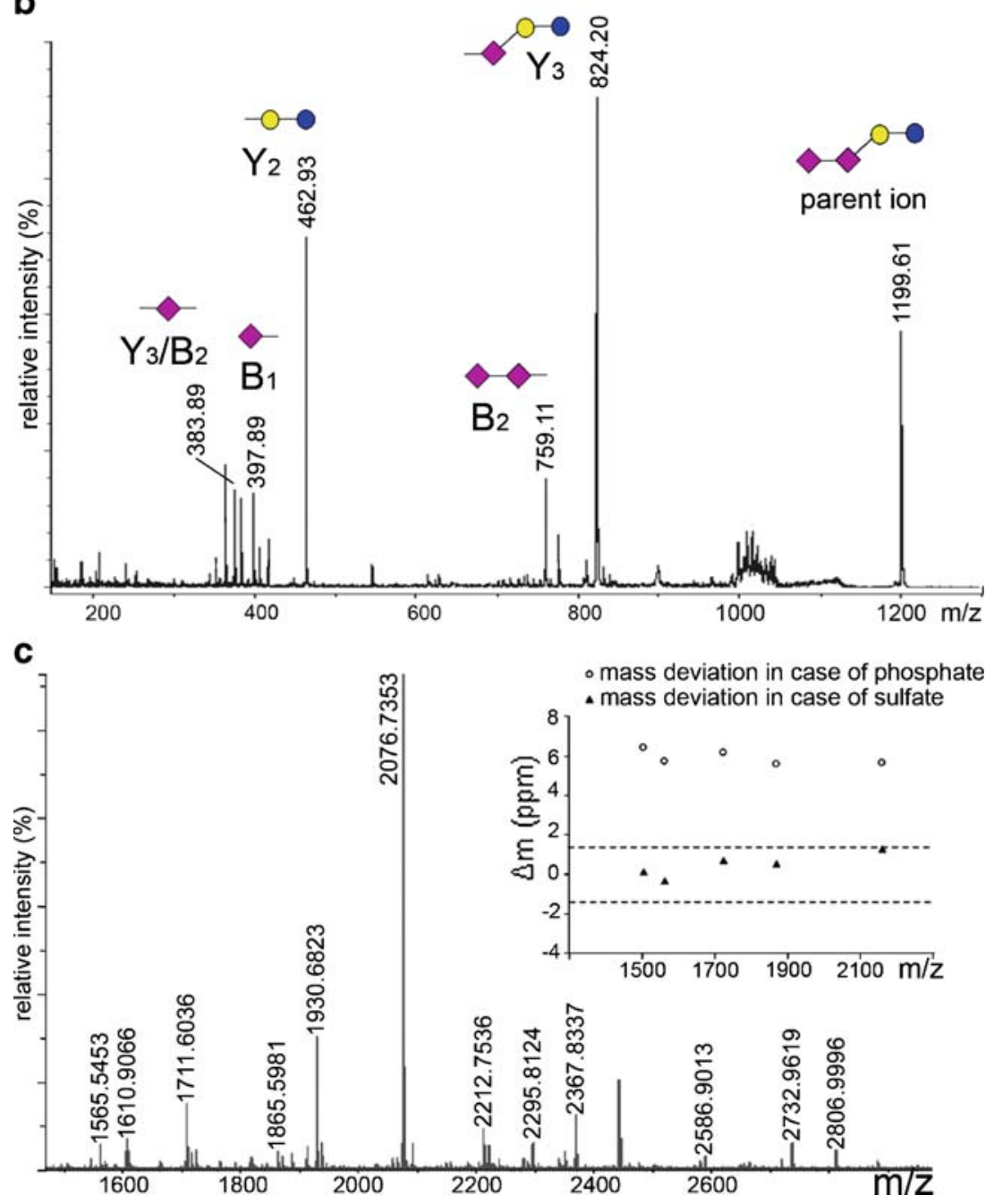

digestion (data not shown). The neutral N-glycan fraction was further analyzed by specific galactosidase enzymes. Many diantennary-size N-glycans were digested by $\beta 1,4-$ galactosidase, whereas $\beta 1,3$-galactosidase did not digest any of the glycans in question. Therefore, we suggest that it is more likely that the fucosylated antennae contain Lex than Lea (data not shown).

Major findings with exoglycosidase digestions are presented in Fig. 3 for the major glycan signals in each separate glycan fraction. N-glycan signals proposed as mannose-type $\mathrm{N}$-glycans were shown by $\alpha$-mannosidase digestion to have non-reducing terminal $\alpha$-mannose residues consistent with the initial assignment. Also the proposed hybrid-type signals were shown to be sensitive to $\alpha$-mannosidase treatment. All detected sialic acid residues in O-glycans were $\alpha 2$-3-linked; whereas in $\mathrm{N}$ glycans also $\alpha 2-6$-linkage was observed, as indicated by the resistance of certain sialylated glycans to $S$. pneumoniae 


\begin{tabular}{|c|c|c|c|c|c|c|}
\hline \multicolumn{4}{|c|}{ Neutral N-glycans, 10 most abundant structures } & \multicolumn{3}{|c|}{ Acidic O-glycans, 5 most abundant structures } \\
\hline Composition & Proposed Structures & Glycosidase & $\begin{array}{c}\text { MS/MS } \\
\text { diagnostic fragments }\end{array}$ & Composition & Proposed Structures & Glycosidase \\
\hline H8N2 & * 1 & 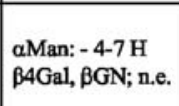 & $\begin{array}{c}0.0 \\
0.000\end{array}$ & S2H1N1 & & $\begin{array}{l}\alpha 3-S A: \\
-1-2 S\end{array}$ \\
\hline H6N2 & & 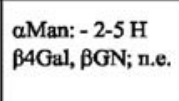 & 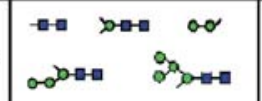 & P1H2N2 & $\mathrm{SO}_{3}^{-} / \mathrm{HPO}_{3}^{-}$ & $\begin{array}{l}\alpha 3 \text {-SA: } \\
\text { n.e. }\end{array}$ \\
\hline H9N2 & * or & $\begin{array}{l}\alpha \text { Man: }-5-8 \mathrm{H} \\
\beta 4 \text { Gal: n.e. } \\
\beta \text { GN: }-0-1 \text { N }\end{array}$ & & $\mathrm{S} 1 \mathrm{H} 2 \mathrm{~N} 2$ & $\diamond$ & $\begin{array}{l}\alpha 3-\mathrm{SA}: \\
-1 \mathrm{~S}\end{array}$ \\
\hline H7N2 & $\begin{array}{l}\text { * } \\
0 \\
0 \\
0\end{array}$ & $\begin{array}{l}\alpha M a n:-3-6 \mathrm{H} \\
\beta 4 G \mathrm{Gal}, \beta G N \text { : n.e. }\end{array}$ & & $\mathrm{S} 2 \mathrm{H} 2 \mathrm{~N} 2$ & & $\begin{array}{l}\alpha 3-S A: \\
-2 S\end{array}$ \\
\hline H5N2 & & $\begin{array}{l}\text { aMan: - 1-4H } \\
\beta 4 \mathrm{Gal}, \beta \mathrm{GN}: \text { n.e. }\end{array}$ & 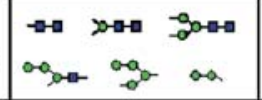 & $\mathrm{S} 2 \mathrm{H} 2 \mathrm{~N} 2 \mathrm{~F} 1$ & & $\begin{array}{l}\alpha 3-S A: \\
-2 S\end{array}$ \\
\hline \multirow[b]{2}{*}{ H5N4 } & \multirow{2}{*}{ 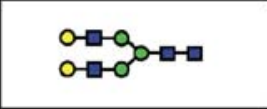 } & \multirow{2}{*}{$\begin{array}{l}\text { aMan: n.e. } \\
\beta 4 \text { Gal: }-2 \mathrm{H} \\
\beta \mathrm{GN}:-0-2 \mathrm{~N}\end{array}$} & \multirow{2}{*}{ 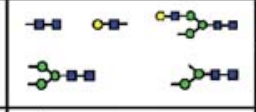 } & \multicolumn{3}{|c|}{ Neutral O-glycans, most abundant structure } \\
\hline & & & & Composition & Proposed Structures & Glycosidase \\
\hline H3N2F1 & & $\begin{array}{l}\text { aMan: - 1-2 H } \\
\text { B4Gal,BGN : n,e. }\end{array}$ & 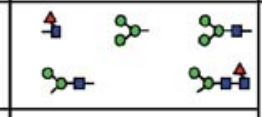 & $\mathrm{H} 2 \mathrm{~N} 2$ & & $\begin{array}{l}\beta 4-G a l: \\
-1 \mathrm{H}\end{array}$ \\
\hline \multirow{2}{*}{ H5N4F1 } & \multirow{2}{*}{ 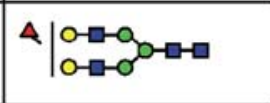 } & \multirow{2}{*}{\begin{tabular}{|l|}
$\alpha M a n:$ n.e. \\
$\beta 4 G a l:-1-2 H$ \\
$\beta G N:-0-2 \mathrm{~N}$ \\
\end{tabular}} & \multirow{2}{*}{ 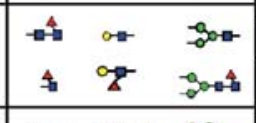 } & \multicolumn{3}{|c|}{ Acidic glycolipid glycans, 4 most abundant structures } \\
\hline & & & & Composition & Proposed Structures & $\begin{array}{l}\text { Diagnostic } \\
\text { fragments }\end{array}$ \\
\hline $\mathrm{H} 4 \mathrm{~N} 2$ & & $\begin{array}{l}\alpha \text { Man: - 0-3 H } \\
\beta 4 \mathrm{Gal}, \beta \mathrm{GN} \text { : n.e. }\end{array}$ & 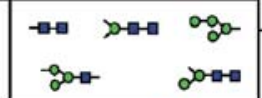 & \multirow[t]{2}{*}{$\mathrm{S} 1 \mathrm{H} 2$} & \multirow{2}{*}{ - } & $\diamond$ \\
\hline \multirow[b]{2}{*}{$\mathrm{H} 6 \mathrm{~N} 3$} & \multirow{2}{*}{$\begin{array}{l}0-0,00-0 \\
0-00\end{array}$} & \multirow{2}{*}{$\begin{array}{l}\alpha \text { Man: - 1-2 H } \\
\beta 4 \text { Gal: }-0-3 \mathrm{H} \\
\beta \mathrm{GN}:-0-1 \mathrm{~N} \\
\end{array}$} & \multirow{3}{*}{ 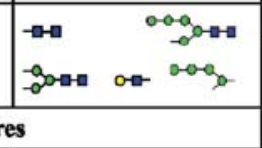 } & & & $\rightarrow-\infty$ \\
\hline & & & & \multirow[t]{2}{*}{$\mathrm{S} 2 \mathrm{H} 2$} & \multirow{2}{*}{$\diamond-\infty$} & \multirow{2}{*}{$\begin{array}{ll}\rightarrow & -\infty \\
\infty & \rightarrow \infty\end{array}$} \\
\hline \multicolumn{3}{|c|}{ Acidic N-glycans, 5 most abundant structures } & & & & \\
\hline Composition & Proposed Structures & Glycosidase & $\begin{array}{c}\text { MS/MS } \\
\text { diagnostic fragments }\end{array}$ & \multirow[b]{2}{*}{ S1H3N1 } & \multirow{2}{*}{$\begin{array}{l}\text { А } \\
\text { В }-0-000\end{array}$} & \multirow{2}{*}{$\begin{array}{cc}A & \text { B } \\
-\infty & -\infty \\
-\infty+\infty & 0\end{array}$} \\
\hline S1H5N4F1 & ${ }^{*} \Delta-0$ & $\begin{array}{l}\alpha 3 S A:-0-1 S \\
S A:-1 S\end{array}$ & 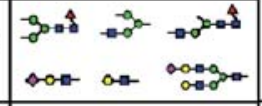 & & & \\
\hline S1H5N4 & *ar & $\begin{array}{l}\alpha 3 S A:-0-1 S \\
S A:-1 S\end{array}$ & 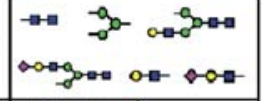 & \multirow[t]{2}{*}{$\mathrm{S} 1 \mathrm{H} 4 \mathrm{~N} 2$} & \multirow{2}{*}{ 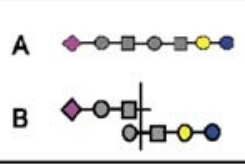 } & \multirow{2}{*}{$\begin{array}{cc}\text { A } & \text { B } \\
-\infty & 0 \\
-\infty+\infty & \end{array}$} \\
\hline \multirow[t]{2}{*}{ S1H6N5F1 } & \multirow{2}{*}{ 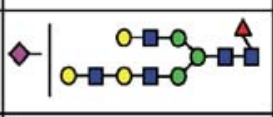 } & \multirow[t]{2}{*}{$\begin{array}{l}\alpha 3 S A:-0-1 S \\
S A:-1 S\end{array}$} & क- & & & \\
\hline & & & & Neutral glyco & pid glycans, most abund & lant structure \\
\hline S2H5N4F1 & $\stackrel{\infty}{\infty} \infty$ & $\begin{array}{l}\alpha 3 S A:-0-2 S \\
S A:-2 S\end{array}$ & क्व०ू- & Composition & Proposed Structures & $\begin{array}{l}\text { Diagnostic } \\
\text { fragments }\end{array}$ \\
\hline $\mathrm{S} 2 \mathrm{H} 5 \mathrm{~N} 4$ & $\begin{array}{l}* 0-a-a+a-a \\
0-a-a-a\end{array}$ & $\begin{array}{l}\alpha 3 S A:-0-2 S \\
S A:-2 S\end{array}$ & & $\mathrm{H} 3 \mathrm{~N} 1$ & $\begin{array}{l}\text { A } 0-0-0 \\
\text { B } \square-0-0-0\end{array}$ & 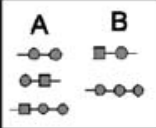 \\
\hline
\end{tabular}

Fig 3 Structure assignments of the most abundant mass spectrometric glycan signals detected in MSCs. N-glycan (left panel), O-glycan (upper right panel) and glycosphingolipid glycan structures (lower right panel) are shown to be determined by glycosidase digestions and/or MS/MS fragmentation of permethylated glycans. Structures

sialidase. The only detected neutral O-glycan core was capped with $\beta 1$-4-linked galactose. Glycosphingolipid glycans were not characterized with glycosidase digestions in the present study. detected in NMR analyses are marked with asterisks. Glycosidase abbreviations are as in the section Materials and Methods. Glycosidase treatment with no effect on the structure is assigned as n.e. Glycan annotations are as in Fig. 1 with the addition of grey circle/square as unspecified hexose $/ N$-acetylhexosamine, respectively

Neutral N- and O-glycan samples of bone marrowderived MSCs were further subjected to enzymatic endo- $\beta$ galactosidase treatment and analyzed by MALDI-TOF mass spectrometry. In both neutral N- and O-glycan spectra 
a signal at $\mathrm{m} / \mathrm{z} 568$ corresponding to $\mathrm{H} 2 \mathrm{~N} 1[\mathrm{M}+\mathrm{Na}]^{+}$ion appeared after endo- $\beta$-galactosidase treatment (data not shown). This represents a characteristic cleavage product of endo- $\beta$-galactosidase. Endo- $\beta$-galactosidase is specific for linear poly-LacNAc substrates and the detected fragment indicates a non-reducing terminal structure Gal-GlcNAc $\beta 1$ 3Galß1-4GlcNAc- (the released H2N1 fragment underlined). The high relative intensity of the cleavage product indicates that it is derived from the breakdown of several poly-LacNAc containing glycans in both $\mathrm{N}$ - and O-glycans.

For further verification of glycan structures of bone marrow-derived MSC glycan fractions were permethylated for MS/MS fragmentation analyses. The detected fragment ions indicative of specific glycan structures are shown in Fig. 3. The fragmentation of a disialylated GD3-type glycosphingolipid glycan is shown as an example in Fig. 2b. Mass spectrometric fragmentation was shown to support the findings of glycome profiling and proposed compositions based on mass matching (Fig. 3). Core fucose was confirmed as the main fucosylation in N-glycans, although fucosylated antennae were also detected. The fragmentation patterns of glycosphingolipid glycans were consistent with the common ganglioside structures GM3, GD3 (Fig. 2b) and GD1, globoside Gb4, and lacto/ neolacto-series poly-LacNAc. All major glycosphingolipid classes were therefore indicated to be expressed in MSCs (Fig. 3). MS/MS fragmentation patterns were also indicative of the presence of linear poly-LacNAc chains in MSC glycans. Candidate glycans carrying poly-LacNAc include the acidic N-glycan S1H6N5F1 and the acidic glycosphingolipid glycan S1H4N2. The fragmentation pattern of the third most abundant acidic N-glycan S1H6N5F1 was consistent with a biantennary $\mathrm{N}$-glycan structure in which one antenna had S1H1N1 composition (putative sialylated LacNAc) and the other H2N2 composition (putative linear polyLacNAc). Especially the presence of a fragmentation product at $\mathrm{m} / \mathrm{z} 2,141.7$ (calc. $\mathrm{m} / \mathrm{z} 2,142.1$ ) corresponding to $\mathrm{S} 1 \mathrm{H} 4 \mathrm{~N} 3 \mathrm{~F} 1[\mathrm{M}+\mathrm{Na}]^{+}$ion supported the assignment. This fragment lacked the putative poly-LacNAc antenna and contained a single free hydroxyl group indicating only one branch point (Fig. 3). The detected fragments from the acidic glycosphingolipid glycan S1H4N2 indicated that the mass spectrometric signal comprised at least 2 structures, of which the structure A was consistent with a linear structure with alternating hexose and $N$-acetylhexosamine residues (Fig. 3), corresponding to putative linear poly-LacNAc. Taken together, the data indicated presence of linear polyLacNAc in $\mathrm{N}$ - and O-glycans, and possibly also in glycosphingolipids of bone marrow-derived MSCs.

Several glycan peaks with 80 Da mass addition were observed in acidic mass spectrometric glycome profiles of MSCs and especially in the osteogenic cells derived from them (Table 1). To discriminate between putative sulfate or phosphate groups, the profiles were further analyzed using MALDI-FTICR-MS in negative-ion mode (Fig. 2c). Here, the masses of sialylated $\mathrm{N}$-glycans could be registered with an average mass deviation of $1.1 \mathrm{ppm}$. Five glycan species with potential sulfation or phosphorylation, which were registered in the same spectrum, were concluded to be sulfated glycans with average mass deviation of $0.6 \mathrm{ppm}$. Phosphorylation could be ruled out on the basis of the large mass deviation (between 5.6 and $6.5 \mathrm{ppm}$ ) between calculated and registered masses (Fig. 2c inset). Unfortunately, acidic O-glycans could not be analyzed in this way, due to the limited amounts of O-glycans available for analyses.

Cell surface glycome analysis by glycan binding proteins

Since the MS and NMR profiling of MSC glycome encompassed the overall cellular glycome, including intracellular glycans, further verification of cell surface presentation of the observed glycan structures was needed. Cytochemical stainings of MSCs and osteoblasts derived thereof were performed using numerous different glycan binding proteins, either lectins or Abs. In Fig. 4 staining of MSCs by sialic acid binding lectins from Maackia amurensis (MAA) and Sambucus nigra (SNA) is shown as an example. The strong staining with MAA (Fig. 4a) indicates $\alpha 2,3$-sialic acid expression on the surface of
Fig 4 Sialic acid expression on MSCs determinated by lectin binding. Maackia amurensis (MAA) binding to $\alpha 2-3$-sialic acid is shown throughout the cell culture (a), whereas Sambucus nigra (SNA) binding to $\alpha 2-6$-sialic acid is relatively weak (b)
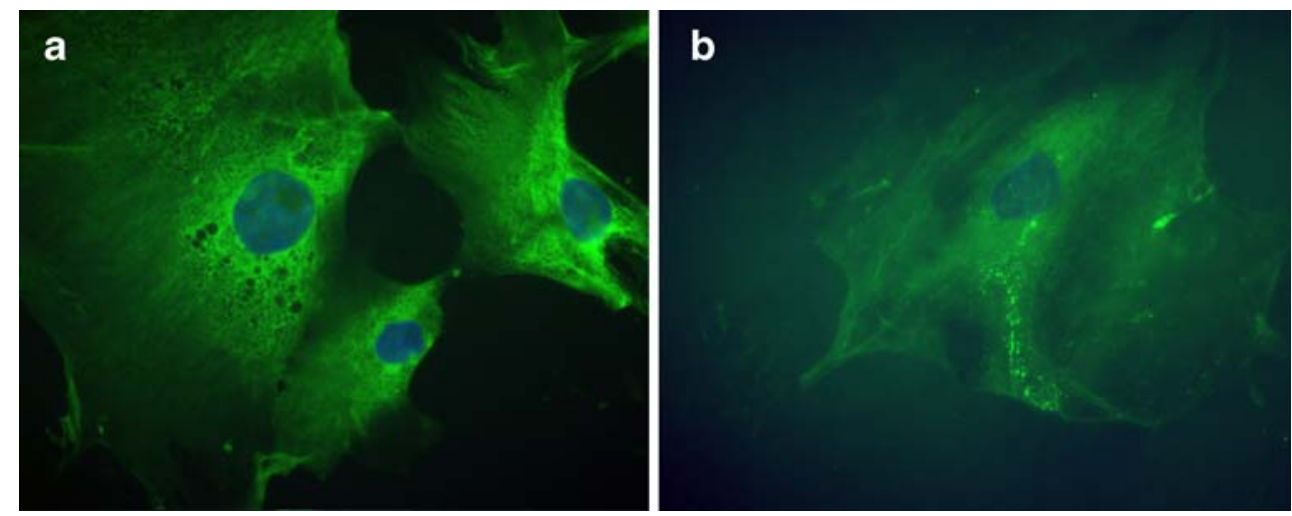
MSCs, in comparison with the relatively weak staining with SNA (Fig. 4b). Both NMR profiling and $\alpha 2-3$-linkage specific sialidase digestion supported the finding that $\alpha 2-3-$ linked sialic acids were abundant in MSCs (Fig. 3).

Many glycan binding proteins showed differential binding to MSCs as compared to osteoblasts. In Fig. $5 \mathrm{Ab}$ against sLex epitope is shown to stain almost exclusively in MSCs (Fig. 5a) when compared to their differentiated counterparts (Fig. 5b). This is in good agreement with our findings of the mass spectrometric analyses that were performed after glycosidase treatments. Fucosidase analyses indicated that neutral N-glycans carry either $\alpha 1-3$ - or $\alpha 1$-4-linked fucose residues, and galactoses in both neutral $\mathrm{N}$ - and O-glycans were shown to be mainly $\beta 1-4$-linked as demonstrated by susceptibility to $\beta 1,4$-galactosidase and resistance to $\beta 1,3$-galactosidase (Fig. 2a). Also, specific sialidase treatment (Fig. 3) and lectin staining (Fig. 4) showed that $\alpha 2-3$-linked sialic acids are abundant in MSCs. The increased fucosylation of sialylated O-glycans (Table 1) could also contribute to enriched sLex epitopes, as the O-glycans were shown using specific sialidase digestions to be $\alpha 2-3$-sialylated (Fig. 3). However, only minor fucosylated glycosphingolipid glycans in MSCs were detected. Therefore, the multifucosylated sialylated Nglycans together with the fucosylated and sialylated Oglycan are likely candidates for the carriers of sLex in MSCs.
The Solanum tuberosum lectin (STA), recognizing mainly linear poly-LacNAc chains, i.e. the blood group i, was shown to pronouncedly stain MSCs (Fig. 5c), whereas staining in their osteogenic derivates was hardly visible (Fig. 5d). In contrast, the cytochemical staining with Phytolacca americana lectin (PWA), recognizing mainly branched poly-LacNAc chains, i.e. blood group antigen I, showed no discrimination between the 2 cell types (data not shown). This is consistent with the presence of very large acidic N-glycans in MSC profile (for example S1H8N7F1 in Fig. 1f) as well as with the mass spectrometric fragmentation analyses demonstrating linear poly-LacNAc type chains in both major acidic N-glycans and glycosphingolipid glycans of MSC (Fig. 3). Also endo- $\beta$ galactosidase digestion liberated $\mathrm{H} 2 \mathrm{~N} 1$ terminal fragments from neutral N-glycans directly indicating the presence of linear poly-LacNAc chains in MSCs. These structural analyses revealed potential STA lectin ligand structures in both N-glycans and glycosphingolipid glycans of MSCs.

Cytochemical lectin stainings of cell surface mannose structures, which were observed in MS and NMR profiling, were also performed. Hippeastrum hybrid (HHA) lectin gave clear staining result of bone marrow-derived MSCs to support the cell surface localization of mannosylated structures (data not shown).

Flow cytometric analyses were performed to further deepen the knowledge of MSC surface glycan structures.
Fig 5 Cytochemical staining of MSCs and their osteogenic counterparts by glycan binding proteins. Anti-sLex Ab stains MSCs (a), while the staining is hardly visible in cells differentiated into osteogenic direction (b). Solanum tuberosum (STA) lectin recognizes epitopes on stem cell surfaces (c), whereas their osteogenic counterparts are hardly recognized (d)
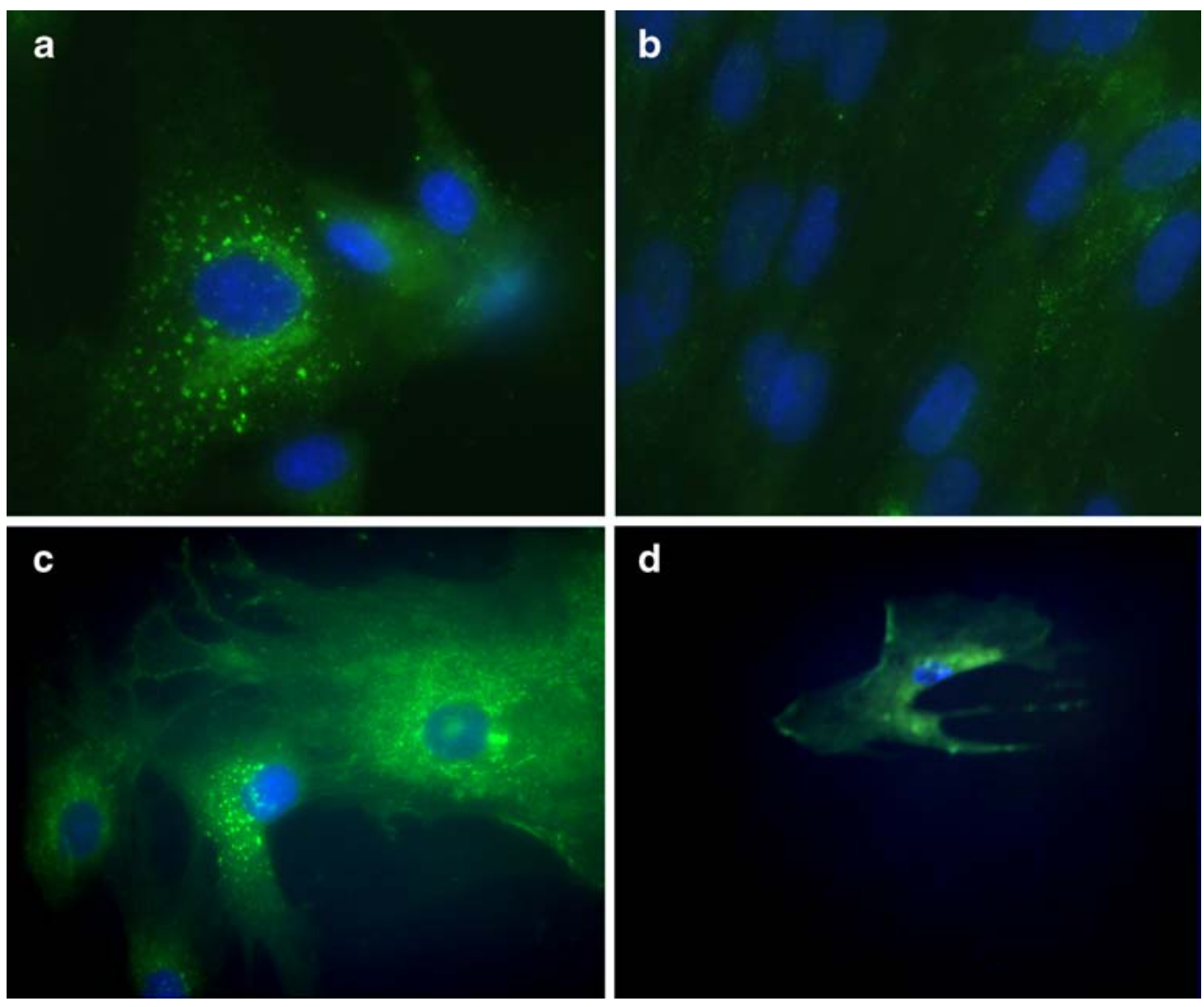
63 different commercially available Abs against glycan epitopes were tested. As an example of this data, Fig. 6 shows increased surface expression of epitopes SSEA-4 (Fig. 6a) and sLex (Fig. 6c) in bone-derived MSCs when compared to their osteogenic counterparts (Fig. 6b,d). In contrast, anti-Lex Ab did not stain the cells (Fig. 6e,f), which was typical of the majority of the Abs screened in the study. Although the staining results showed clear SSEA-4 epitope expression in stem cells (Fig. 6a), no corresponding signal, with S1H4N1 composition, could be detected in mass spectra of acidic glycosphingolipids. Instead, very low intensity signal of SSEA-3 composition (H4N1) was seen in neutral glycosphingolipid profile of differentiated osteoblasts. Interestingly, hardly any staining with SSEA-3 $\mathrm{Ab}$ was detected in any of the cells analyzed (data not shown). Flow cytometric analysis of sLex epitope expression (Fig. 6c) was not as demonstrative as immunostaining result described above (Fig. 5a). Here, approximately 70\% of MSCs (Fig. 6c) and still more than 35\% of osteoblasts (Fig. 6d) were shown to be sLex positive. The contradictory results are likely due to methodological differences in the 2 staining procedures.

\section{Discussion}

Stem cell glycosylation has been shown to have characteristic features in numerous reports relying on lectin and glycan-antibody stainings mainly in embryonic stem cells [25-27, 39]. In this study we have widened the research on human stem cell glycosylation into MSCs, which hold an enormous therapeutic potential, especially in regenerative medicine. We combined mass spectrometric and NMR spectroscopic glycan profiling, verified by enzymatic glycosidase digestions and mass spectrometric fragmentation, with analysis with glycan binding proteins, using both fluorescence microscopy and flow cytometry. This unique combination of methods verifies that certain glycan structures provide a signature which allows discrimination between MSCs and their osteogenic counterparts. Here,
Fig 6 Flow cytometry histograms of glycan antibody binding in MSCs and their osteogenic counterparts. AntiSSEA-4 (a, b), anti-sLex (c, d) and anti-Lex (e, f) Ab stainings are visualized in MSCs $(\mathbf{a}, \mathbf{c}, \mathbf{e})$ and in differentiated osteoblasts $(\mathbf{b}, \mathbf{d}, \mathbf{f})$. Histogram plots with the overlay images of staining antibodies are shown with red fill in comparison to histogram plot of unstained cells (grey fill)
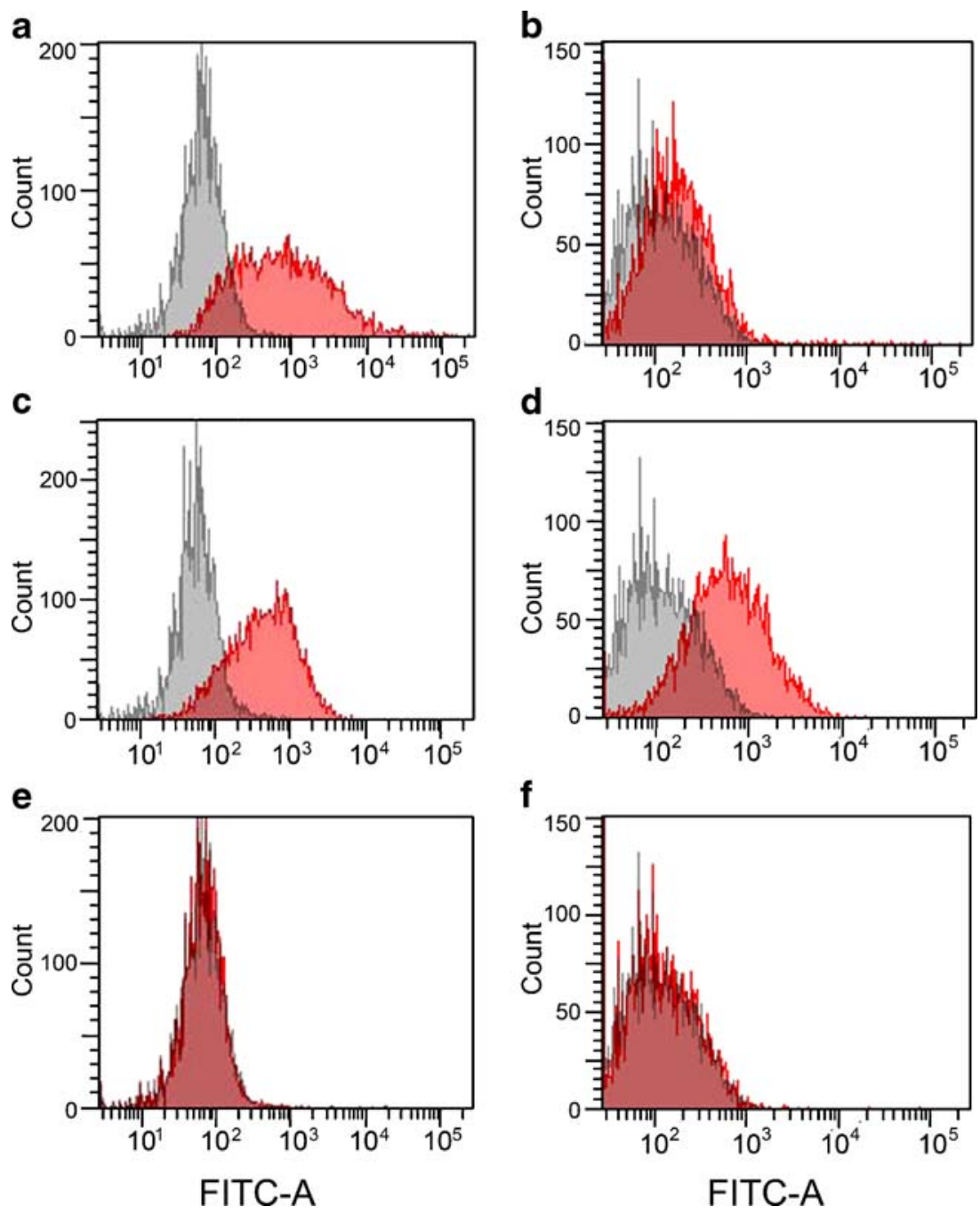
some of the glycan epitopes found to be characteristic of MSCs and their differentiation are discussed.

Our data imply that a relatively high amount of high mannose glycans in the total glycan pool might be a common feature of stem cell glycomes, including human MSCs as shown in the present study, embryonic stem cells (unpublished data) and hematopoietic stem cells [28]. It should be realized that the total glycomes include also intracellular glycans, and these typically contain more highmannose glycans than e.g. individual secreted proteins or glycans from plasma membranes. The major ER and Golgi type glycans in the glycan profile might reflect the metabolic status of cells. However, in the case of cultured cells, such as the MSCs in the present study, cell culture conditions may have a substantial effect on glycomes. It would be a major challenge to increase the sensitivity of the assay to enable the analysis of stem cells isolated directly from tissues. So far this has been achieved only for hematopoietic stem cells, which were also shown to contain relatively high amounts of high-mannose glycans [28]. The glycomes of the stem cells cultured under standard conditions are useful for the characterization of cells aimed for therapy, even when the glycomes may not correspond to the natural glycosylation of the cells.

We were able to observe increased expression of linear poly- $N$-acetyllactosamine (poly-LacNAc) chains in MSCs as compared with osteoblasts by mass spectrometric fragmentation analysis, endo- $\beta$-galactosidase digestion, and Solanum tuberosum lectin (STA) staining. PolyLacNAcs have been shown to undergo structural changes during human development, wherein linear chains in fetal blood cells (i-antigen) are changed to branched chains (Iantigen) in the adult [40]. However, early embryonic cells express large branched poly-LacNAc (embryoglycan), whereas the i-antigen appears in postimplantation embryos [21]. The SSEA-1 Lex structure, which is commonly used as a marker for mouse embryonic stem cells, is expressed within embryoglycan, and even though human embryonic cells do not express SSEA-1, they contain embryoglycan consisting of poly-LacNAc, that is considered to be an evolutionary conserved glycan backbone [21]. In general, poly-LacNAcs are thought to act as scaffolds presenting glycan epitopes to lectins in a multivalent fashion. For example, the galectins, a family of $\beta$-galactoside binding lectins involved in a wide range of adhesion and signaling phenomena [41], have higher affinity for poly-LacNAcs than for single LacNAc units [42-44]. Galectins are hypothesized to modulate their biological functions according to fine specificities for target glycans [44]. MSCs express galectins [45], and the immunomodulatory effects of galectins have been shown to reduce GvHD in a mouse model [46]. In addition, exposure to galectin-1 induces skeletal muscle differentiation of human fetal MSCs [47].
The expression of SSEA-4, but not SSEA-3, on bone marrow-derived MSCs was demonstrated in this study by antibody staining analyzed by flow cytometry. However, very low levels of either of the corresponding glycosphingolipid glycan signals were observed in mass spectrometric profiles. The glycosphingolipid markers SSEA-3 and SSEA4 are considered to be markers of human embryonic stem cells [27, 39, 48]. However, they do not seem to be essential for pluripotency [49]. Our results confirm the previously reported expression of SSEA-4 also on bone marrow MSCs [50-53]. Interestingly, one of the studies reported SSEA-4 expression to markedly increase under serum free culturing conditions [51]. In contrast to the lack of SSEA-3 expression reported here, evidence of SSEA-3 expression in MSCs does exist $[50,52]$. However, absence of both SSEA-3 and SSEA-4 on adult bone marrow MSCs has also been reported [54]. The contradictory results are likely due to either cell line-specific expression of these epitopes or differences in culture conditions.

We observed the presence of multiple ganglioseries glycosphingolipids on both MSCs and their differentiated variants. We detected changes in glycosphingolipid composition during the differentiation of MSCs, such as a tendency of smaller GM3/GD3 structures to change into larger gangliosides, including GD1. Several ganglioseries glycosphingolipids are expressed on human embryonic stem cells, and differentiation has been reported to induce a change in their ganglioside profile [39]. Especially, increased expression of disialylgangliosides, including GD3 and GD2, after embryonic stem cell differentiation, has been reported [39]. GD2 has previously been reported to be a potential marker of bone marrow-derived MSCs [55], but our results do not support this finding, since we did not observe GD2 (composition S2H2N1) at all in MSCs, but rather in osteoblasts derived from them. Human periodontal bone marrow MSCs have been reported to express GM1 [56], which was found also in the present study by MS/MS fragmentation, whereas after neuronal differentiation both GM1 and GT1b were detected [56]. In contrast to the present study, no other gangliosides, like GM3/GD3, could be detected [56]. The differences may be caused by methodological differences between the two studies or different bone marrow sources used in them.

Sulfated carbohydrate epitopes, which we observed to be markedly enriched both in the N-glycan and O-glycan profiles of osteogenically differentiated MSCs, are involved in a variety of biological recognition events. Some galectins, especially galectins $1-3$, have been shown to bind 3 '-sulfated LacNAcs better than their unsulfated counterparts [44]. Sulfation affects also the binding of certain siglecs, a family of sialic acid binding lectins involved in the regulation of the immune system [57], to their ligands. L-selectin ligand glycoproteins, which are 
involved in leukocyte-endothelium interactions, are known to carry sulfated sLex structures [58]. Keratan sulfate epitopes Tra-1-60 and Tra-1-81 have been reported as markers of embryonic stem cells [27, 39]. These sulfated poly-LacNAc structures (sulfated forms of the i-antigen) are closely related to the structures observed enriched in differentiated osteoblasts in the present study. The production of sulfated glycosaminoglycans, such as keratan sulfate, is considered a hallmark of MSC differentiation commitment into osteogenic lineage and it co-occurs with increased expression of glycosaminoglycan biosynthetic enzymes [59]. It is also noteworthy that the bone sialoprotein, an osteoblast-associated marker, which is expressed exclusively in bone and particularly during early stages of bone formation [60], has been reported by metabolic labeling to contain sulfated $\mathrm{N}$ - and O-glycans in rats [61]. However, sulfated glycans have not been observed in human bone sialoprotein [62].

In the present study, sialyl-Lewis x (sLex) is introduced as a novel characteristic glycan epitope expressed on human MSCs derived from bone marrow and to some extent also on osteogenically differentiated cells derived from them. sLex is best known as a selectin ligand, and for its involvement in leukocyte homing as well as in cancer metastasis $[63,64]$. In addition, sLex has been reported to mediate fucosylation-dependent homing of both hematopoietic $[65,66]$ and mesenchymal [67] stem cells into bone marrow. MSCs have also been shown to roll on endothelial cells in a P-selectin-dependent manner [68]. Interestingly, a major selectin ligand PSGL-1 carries sLex on O-glycans [69], whereas selectin ligands carried on N-glycans have also been reported [70], especially in hematopoietic and mesenchymal stem cells $[67,71]$. In the present study we identified both $\mathrm{N}$ - and O-glycans as potential carriers of sLex epitope in MSCs.

We report here that $\alpha 2-3$-linked sialic acid, which is also terminal residue of the sLex epitope, is a typical structure on the surface of MSCs, Although these sialic acids are common terminal glycan structures, the ratio of $\alpha 2-3-$ and $\alpha 2-6$-sialylation may affect intercellular interactions or differentiation of cells by modulating the binding of glycan receptors, such as siglec 2 (CD22) [72, 73] or selectin-sLex adhesion. $\alpha 2-3$-sialylation has also been shown to regulate T-cell biology through inhibiting galectin-1 binding [74]. Interestingly, terminal $\alpha 2-3$-sialic acid on a $\mathrm{N}$-glycan has been shown to inhibit binding of CD44 to hyaluronic acid [75]. As MSCs express $\alpha 2-3$-sialylated glycoform of CD44 [67], $\alpha 2-3$-sialylation may regulate MSC adhesion to the extracellular matrix. We have previously shown $\alpha 2-3-$ sialylation to be increased also on cord blood CD133+ hematopoietic stem cells as compared to differentiated CD133- cells [28]. In the present study, MSC O-glycans were shown to contain sialic acid exclusively in $\alpha 2-3$ linkage, indicating differential regulation of sialylation between the different glycan classes.

In conclusion, we analyzed the glycome of bone marrow-derived MSCs using MS and NMR profiling, further structure verification and a broad range of glycan binding proteins. Comparison of the obtained data to the profiles of osteogenically differentiated cells clearly indicated cell type specific variation in the glycosylation patterns. Certain glycan structures seem to be indicative of the "stemness" nature of cells. The conservation of a specific glycan structure between different stem cell types within the same species, or conservation between different species on a certain stem cell type, may be an indication of an essential function for the glycan structure in multipotent cells [19]. At least to our knowledge, no glycosylation studies on MSCs from different species have been conducted, but we have demonstrated here similarities in stem cell glycosylation between human MSCs and both human embryonic stem cells [22-24] and hematopoietic stem cells [28]. It seems evident that glycan structures may be"switched on" and "off" on cell surfaces several times during cellular differentiation in developmental processes, as implied by the transition between linear and branched poly-LacNAc structures [21]. Here, similar transition in multiple glycan structures was demonstrated during MSC differentiation into osteogenic direction. The more precise biological functions of these glycosylation characteristics remain to be defined in the future.

Acknowledgments We would like to thank Teija Kupari and Sirkka Mannelin for skillful technical assistance. We thank Dr. Bogdan Bogdanov for his assistance with the acquisition of the FTICR-MS data. The present study was supported by the Finnish Funding Agency for Technology and Innovation (TEKES).

Open Access This article is distributed under the terms of the Creative Commons Attribution Noncommercial License, which permits any noncommercial use, distribution, and reproduction in any medium, provided the original author(s) and source are credited.

\section{References}

1. Moore, K.E., Mills, J.F., Thornton, M.M.: Alternative sources of adult stem cells: a possible solution to the embryonic stem cell debate. Gend. Med. 3, 161-168 (2006). doi:10.1016/S1550-8579 (06)80204-4

2. Pessina, A., Gribaldo, L.: The key role of adult stem cells: therapeutic perspectives. Curr. Med. Res. Opin. 22, 2287-2300 (2006). doi:10.1185/030079906X148517

3. Porada, C.D., Zanjani, E.D., meida-Porad, G.: Adult mesenchymal stem cells: a pluripotent population with multiple applications. Curr. Stem Cell Res. Ther. 1, 365-369 (2006)

4. Prockop, D.J.: Marrow stromal cells as stem cells for nonhematopoietic tissues. Science 276, 71-74 (1997). doi:10.1126/ science. 276.5309 .71 
5. Rochefort, G.Y., Delorme, B., Lopez, A., Herault, O., Bonnet, P., Charbord, P., Eder, V., Domenech, J.: Multipotential mesenchymal stem cells are mobilized into peripheral blood by hypoxia. Stem Cells 24, 2202-2208 (2006). doi:10.1634/ stemcells.2006-0164

6. Bieback, K., Kern, S., Kluter, H., Eichler, H.: Critical parameters for the isolation of mesenchymal stem cells from umbilical cord blood. Stem Cells 22, 625-634 (2004). doi:10.1634/stemcells. 22-4-625

7. Erices, A., Conget, P., Minguell, J.J.: Mesenchymal progenitor cells in human umbilical cord blood. Br. J. Haematol. 109, 235 242 (2000). doi:10.1046/j.1365-2141.2000.01986.x

8. Katritsis, D.G., Sotiropoulou, P., Giazitzoglou, E., Karvouni, E., Papamichail, M.: Electrophysiological effects of intracoronary transplantation of autologous mesenchymal and endothelial progenitor cells. Europace 9, 167-171 (2007). doi:10.1093/europace/ eul184

9. Zaidi, N., Nixon, A.J.: Stem cell therapy in bone repair and regeneration. Ann. N Y Acad.Sci. 1117, 62-72 (2007). doi:10.1196/ annals. 1402.074

10. Horwitz, E.M., Gordon, P.L., Koo, W.K., Marx, J.C., Neel, M.D., McNall, R.Y., Muul, L., Hofmann, T.: Isolated allogeneic bone marrow-derived mesenchymal cells engraft and stimulate growth in children with osteogenesis imperfecta: implications for cell therapy of bone. Proc. Natl. Acad. Sci. U S A 99, 8932-8937 (2002). doi:10.1073/pnas.132252399

11. Le, B.K., Rasmusson, I., Sundberg, B., Gotherstrom, C., Hassan, M., Uzunel, M., Ringden, O.: Treatment of severe acute graftversus-host disease with third party haploidentical mesenchymal stem cells. Lancet 363, 1439-1441 (2004). doi:10.1016/S01406736(04)16104-7

12. Moviglia, G.A., Fernandez, V.R., Brizuela, J.A., Saslavsky, J., Vrsalovic, F., Varela, G., Bastos, F., Farina, P., Etchegaray, G., Barbieri, M., Martinez, G., Picasso, F., Schmidt, Y., Brizuela, P., Gaeta, C.A., Costanzo, H., Moviglia Brandolino, M.T., Merino, S., Pes, M.E., Veloso, M.J., Rugilo, C., Tamer, I., Shuster, G.S.: Combined protocol of cell therapy for chronic spinal cord injury. Report on the electrical and functional recovery of two patients. Cytotherapy 8, 202-209 (2006). doi:10.1080/ 14653240600736048

13. Varki, A.: Biological roles of oligosaccharides: all of the theories are correct. Glycobiology 3, 97-130 (1993). doi:10.1093/glycob/3.2.97

14. Haltiwanger, R.S., Lowe, J.B.: Role of glycosylation in development. Annu. Rev. Biochem. 73, 491-537 (2004). doi:10.1146/ annurev.biochem.73.011303.074043

15. Ohtsubo, K., Marth, J.D.: Glycosylation in cellular mechanisms of health and disease. Cell 126, 855-867 (2006). doi:10.1016/j. cell.2006.08.019

16. Yu, R.K., Yanagisawa, M.: Glycobiology of neural stem cells. CNS Neurol. Disord. Drug Targets 5, 415-423 (2006). doi:10.2174/ 187152706777950675

17. Marth, J.D.: Will the transgenic mouse serve as a Rosetta Stone to glycoconjugate function? Glycoconj. J. 11, 3-8 (1994). doi:10.1007/ BF00732424

18. Lowe, J.B., Marth, J.D.: A genetic approach to mammalian glycan function. Annu. Rev. Biochem. 72, 643-691 (2003). doi:10.1146/ annurev.biochem.72.121801.161809

19. Gagneux, P., Varki, A.: Evolutionary considerations in relating oligosaccharide diversity to biological function. Glycobiology $\mathbf{9}$, 747-755 (1999). doi:10.1093/glycob/9.8.747

20. Lanctot, P.M., Gage, F.H., Varki, A.P.: The glycans of stem cells. Curr. Opin. Chem. Biol. 11, 373-380 (2007). doi:10.1016/j. cbpa.2007.05.032

21. Muramatsu, T., Muramatsu, H.: Carbohydrate antigens expressed on stem cells and early embryonic cells. Glycoconj. J. 21, 41-45 (2004). doi:10.1023/B:GLYC.0000043746.77504.28
22. Venable, A., Mitalipova, M., Lyons, I., Jones, K., Shin, S., Pierce, M., Stice, S.: Lectin binding profiles of SSEA-4 enriched, pluripotent human embryonic stem cell surfaces. BMC Dev. Biol. 5, 15 (2005). doi:10.1186/1471-213X-5-15

23. Wearne, K.A., Winter, H.C., O'Shea, K., Goldstein, I.J.: Use of lectins for probing differentiated human embryonic stem cells for carbohydrates. Glycobiology 16, 981-990 (2006). doi:10.1093/ glycob/cwl019

24. Wearne, K.A., Winter, H.C., Goldstein, I.J.: Temporal changes in the carbohydrates expressed on BG01 human embryonic stem cells during differentiation as embryoid bodies. Glycoconj. J. 25, 121-136 (2008). doi:10.1007/s10719-007-9064-x

25. Badcock, G., Pigott, C., Goepel, J., Andrews, P.W.: The human embryonal carcinoma marker antigen TRA-1-60 is a sialylated keratan sulfate proteoglycan. Cancer Res. 59, 4715-4719 (1999)

26. Kannagi, R., Cochran, N.A., Ishigami, F., Hakomori, S., Andrews, P.W., Knowles, B.B., Solter, D.: Stage-specific embryonic antigens (SSEA-3 and -4) are epitopes of a unique globo-series ganglioside isolated from human teratocarcinoma cells. EMBO J. 2, 2355-2361 (1983)

27. Adewumi, O., Aflatoonian, B., hrlund-Richter, L., Amit, M., Andrews, P.W., Beighton, G., Bello, P.A., Benvenisty, N., Berry, L.S., Bevan, S., Blum, B., Brooking, J., Chen, K.G., Choo, A.B., Churchill, G.A., Corbel, M., Damjanov, I., Draper, J.S., Dvorak, P., Emanuelsson, K., Fleck, R.A., Ford, A., Gertow, K., Gertsenstein, M., Gokhale, P.J., Hamilton, R.S., Hampl, A., Healy, L.E., Hovatta, O., Hyllner, J., Imreh, M.P., Itskovitz-Eldor, J., Jackson, J., Johnson, J.L., Jones, M., Kee, K., King, B.L., Knowles, B.B., Lako, M., Lebrin, F., Mallon, B.S., Manning, D., Mayshar, Y., McKay, R.D., Michalska, A.E., Mikkola, M., Mileikovsky, M., Minger, S.L., Moore, H.D., Mummery, C.L., Nagy, A., Nakatsuji, N., O’Brien, C.M., Oh, S.K., Olsson, C., Otonkoski, T., Park, K.Y., Passier, R., Patel, H., Patel, M., Pedersen, R., Pera, M.F., Piekarczyk, M.S., Pera, R.A., Reubinoff, B.E., Robins, A.J., Rossant, J., Rugg-Gunn, P., Schulz, T.C., Semb, H., Sherrer, E.S., Siemen, H., Stacey, G.N., Stojkovic, M., Suemori, H., Szatkiewicz, J., Turetsky, T., Tuuri, T., van den, B.S., Vintersten, K., Vuoristo, S., Ward, D., Weaver, T.A., Young, L.A., Zhang, W.: Characterization of human embryonic stem cell lines by the International Stem Cell Initiative. Nat. Biotechnol. 25, 803-816 (2007). doi:10.1038/nbt1318

28. Hemmoranta, H., Satomaa, T., Blomqvist, M., Heiskanen, A., Aitio, O., Saarinen, J., Natunen, J., Partanen, J., Laine, J., Jaatinen, T.: N-glycan structures and associated gene expression reflect the characteristic $\mathrm{N}$-glycosylation pattern of human hematopoietic stem and progenitor cells. Exp. Hematol. 35, 1279-1292 (2007). doi:10.1016/j.exphem.2007.05.006

29. Leskelä, H.V., Risteli, J., Niskanen, S., Koivunen, J., Ivaska, K.K., Lehenkari, P.: Osteoblast recruitment from stem cells does not decrease by age at late adulthood. Biochem. Biophys. Res. Commun. 311, 1008-1013 (2003). doi:10.1016/j.bbrc.2003.10.095

30. Heiskanen, A., Satomaa, T., Tiitinen, S., Laitinen, A., Mannelin, S., Impola, U., Mikkola, M., Olsson, C., Miller-Podraza, H., Blomqvist, M., Olonen, A., Salo, H., Lehenkari, P., Tuuri, T., Otonkoski, T., Natunen, J., Saarinen, J., Laine, J.: N-glycolylneuraminic acid xenoantigen contamination of human embryonic and mesenchymal stem cells is substantially reversible. Stem Cells 25, 197-202 (2007). doi:10.1634/stemcells.2006-0444

31. Huang, Y., Mechref, Y., Novotny, M.V.: Microscale nonreductive release of O-linked glycans for subsequent analysis through MALDI mass spectrometry and capillary electrophoresis. Anal. Chem. 73, 6063-6069 (2001). doi:10.1021/ac015534c

32. Miller-Podraza, H., Lanne, B., Angstrom, J., Teneberg, S., Milh, M.A., Jovall, P.A., Karlsson, H., Karlsson, K.A.: Novel binding epitope for Helicobacter pylori found in neolacto carbohydrate 
chains: structure and cross-binding properties. J. Biol. Chem. 280, 19695-19703 (2005). doi:10.1074/jbc.M412688200

33. Aoki, K., Perlman, M., Lim, J.M., Cantu, R., Wells, L., Tiemeyer, M.: Dynamic developmental elaboration of N-linked glycan complexity in the Drosophila melanogaster embryo. J. Biol. Chem. 282, 9127-9142 (2007). doi:10.1074/jbc.M606711200

34. Kang, P., Mechref, Y., Klouckova, I., Novotny, M.V.: Solid-phase permethylation of glycans for mass spectrometric analysis. Rapid Commun. Mass Spectrom. 19, 3421-3428 (2005). doi:10.1002/ rcm. 2210

35. Martin, M.J., Muotri, A., Gage, F., Varki, A.: Human embryonic stem cells express an immunogenic nonhuman sialic acid. Nat. Med. 11, 228-232 (2005). doi:10.1038/nm1181

36. Fu, D., Chen, L., O'Neill, R.A.: A detailed structural characterization of ribonuclease $\mathrm{B}$ oligosaccharides by $1 \mathrm{H}$ NMR spectroscopy and mass spectrometry. Carbohydr. Res. 261, 173186 (1994). doi:10.1016/0008-6215(94)84015-6

37. Hard, K., Van, Z.G., Moonen, P., Kamerling, J.P., Vliegenthart, F.G.: The Asn-linked carbohydrate chains of human TammHorsfall glycoprotein of one male. Novel sulfated and novel Nacetylgalactosamine-containing $\mathrm{N}$-linked carbohydrate chains. Eur. J. Biochem. 209, 895-915 (1992). doi:10.1111/j.14321033.1992.tb17362.x

38. Helin, J., Maaheimo, H., Seppo, A., Keane, A., Renkonen, O.: Stepwise transfer of alpha-D-Galp-(1->3)-beta-D-Galp-(1->4)beta-D-GlcpNAc sequences to 3-OH and 6-OH of distal galactose residues in bi-, tri-, and tetra-antennary asialo-glycans of $\mathrm{N}$-linked complex type. Carbohydr. Res. 266, 191-209 (1995). doi:10.1016/ 0008-6215(94)00272-H

39. Draper, J.S., Pigott, C., Thomson, J.A., Andrews, P.W.: Surface antigens of human embryonic stem cells: changes upon differentiation in culture. J. Anat. 200, 249-258 (2002). doi:10.1046/ j.1469-7580.2002.00030.x

40. Fukuda, M., Fukuda, M.N., Hakomori, S.: Developmental change and genetic defect in the carbohydrate structure of band 3 glycoprotein of human erythrocyte membrane. J. Biol. Chem. 254, 3700-3703 (1979)

41. Leffler, H., Carlsson, S., Hedlund, M., Qian, Y., Poirier, F.: Introduction to galectins. Glycoconj. J. 19, 433-440 (2004). doi:10.1023/B:GLYC.0000014072.34840.04

42. Leppänen, A., Stowell, S., Blixt, O., Cummings, R.D.: Dimeric galectin-1 binds with high affinity to alpha2,3-sialylated and nonsialylated terminal $\mathrm{N}$-acetyllactosamine units on surface-bound extended glycans. J. Biol. Chem. 280, 5549-5562 (2005). doi:10.1074/jbc.M412019200

43. Stowell, S.R., as-Baruffi, M., Penttila, L., Renkonen, O., Nyame, A.K., Cummings, R.D.: Human galectin-1 recognition of poly-Nacetyllactosamine and chimeric polysaccharides. Glycobiology 14, 157-167 (2004). doi:10.1093/glycob/cwh018

44. Stowell, S.R., Arthur, C.M., Mehta, P., Slanina, K.A., Blixt, O., Leffler, H., Smith, D.F., Cummings, R.D.: Galectin-1, -2 , and -3 exhibit differential recognition of sialylated glycans and blood group antigens. J. Biol. Chem. 283, 10109-10123 (2008). doi:10. 1074/jbc.M709545200

45. Kadri, T., Lataillade, J.J., Doucet, C., Marie, A., Ernou, I., Bourin, P., Joubert-Caron, R., Caron, M., Lutomski, D.: Proteomic study of Galectin-1 expression in human mesenchymal stem cells. Stem Cells Dev. 14, 204-212 (2005). doi:10.1089/scd.2005.14.204

46. Baum, L.G., Blackall, D.P., rias-Magallano, S., Nanigian, D., Uh, S.Y., Browne, J.M., Hoffmann, D., Emmanouilides, C.E., Territo, M.C., Baldwin, G.C.: Amelioration of graft versus host disease by galectin-1. Clin. Immunol. 109, 295-307 (2003). doi:10.1016/j. clim.2003.08.003

47. Chan, J., O’Donoghue, K., Gavina, M., Torrente, Y., Kennea, N., Mehmet, H., Stewart, H., Watt, D.J., Morgan, J.E., Fisk, N.M.: Galectin-1 induces skeletal muscle differentiation in human fetal mesenchymal stem cells and increases muscle regeneration. Stem Cells 24, 1879-1891 (2006). doi:10.1634/stemcells.20050564

48. Thomson, J.A., Itskovitz-Eldor, J., Shapiro, S.S., Waknitz, M.A., Swiergiel, J.J., Marshall, V.S., Jones, J.M.: Embryonic stem cell lines derived from human blastocysts. Science 282, 1145-1147 (1998). doi:10.1126/science.282.5391.1145

49. Brimble, S.N., Sherrer, E.S., Uhl, E.W., Wang, E., Kelly, S., Merrill, A.H., Jr., Robins, A.J., Schulz, T.C.: The cell surface glycosphingolipids SSEA-3 and SSEA-4 are not essential for human ESC pluripotency. Stem Cells 25, 54-62 (2007). doi:10.1634/stemcells.2006-0232

50. Gang, E.J., Bosnakovski, D., Figueiredo, C.A., Visser, J.W., Perlingeiro, R.C.: SSEA-4 identifies mesenchymal stem cells from bone marrow. Blood 109, 1743-1751 (2007). doi:10.1182/blood2005-11-010504

51. Battula, V.L., Bareiss, P.M., Treml, S., Conrad, S., Albert, I., Hojak, S., Abele, H., Schewe, B., Just, L., Skutella, T., Buhring, H.J.: Human placenta and bone marrow derived MSC cultured in serumfree, b-FGF-containing medium express cell surface frizzled-9 and SSEA-4 and give rise to multilineage differentiation. Differentiation 75, 279-291 (2007). doi:10.1111/j.1432-0436.2006.00139.x

52. Peiffer, I., Eid, P., Barbet, R., Li, M.L., Oostendorp, R.A., Haydont, V., Monier, M.N., Milon, L., Fortunel, N., Charbord, P., Tovey, M., Hatzfeld, J., Hatzfeld, A.: A sub-population of high proliferative potential-quiescent human mesenchymal stem cells is under the reversible control of interferon alpha/beta. Leukemia 21, 714-724 (2007). doi:10.1038/sj.leu.2404589

53. Roubelakis, M.G., Pappa, K.I., Bitsika, V., Zagoura, D., Vlahou, A., Papadaki, H.A., Antsaklis, A., Anagnou, N.P.: Molecular and proteomic characterization of human mesenchymal stem cells derived from amniotic fluid: comparison to bone marrow mesenchymal stem cells. Stem Cells Dev. 16, 931-952 (2007). doi:10.1089/scd.2007.0036

54. Guillot, P.V., Gotherstrom, C., Chan, J., Kurata, H., Fisk, N.M.: Human first-trimester fetal MSC express pluripotency markers and grow faster and have longer telomeres than adult MSC. Stem Cells 25, 646-654 (2007). doi:10.1634/stemcells.2006-0208

55. Martinez, C., Hofmann, T.J., Marino, R., Dominici, M., Horwitz, E.M.: Human bone marrow mesenchymal stromal cells express the neural ganglioside GD2: a novel surface marker for the identification of MSCs. Blood 109, 4245-4248 (2007). doi:10.1182/blood-2006-08-039347

56. Kwak, D.H., Yu, K., Kim, S.M., Lee, D.H., Kim, S.M., Jung, J.U., Seo, J.W., Kim, N., Lee, S., Jung, K.Y., You, H.K., Kim, H.A., Choo, Y.K.: Dynamic changes of gangliosides expression during the differentiation of embryonic and mesenchymal stem cells into neural cells. Exp. Mol. Med. 38, 668-676 (2006)

57. Varki, A., Angata, T.: Siglecs - the major subfamily of I-type lectins. Glycobiology 16, 1R-27R (2006). doi:10.1093/glycob/cwj008

58. Rosen, S.D.: Endothelial ligands for L-selectin: from lymphocyte recirculation to allograft rejection. Am. J. Pathol. 155, 1013-1020 (1999)

59. Muller, B., Prante, C., Gastens, M., Kuhn, J., Kleesiek, K., Gotting, C.: Increased levels of xylosyltransferase I correlate with the mineralization of the extracellular matrix during osteogenic differentiation of mesenchymal stem cells. Matrix Biol. 27, 139149 (2008). doi:10.1016/j.matbio.2007.09.005

60. Liu, F., Malaval, L., Aubin, J.E.: Global amplification polymerase chain reaction reveals novel transitional stages during osteoprogenitor differentiation. J. Cell Sci. 116, 1787-1796 (2003). doi: $10.1242 /$ jcs. 00376

61. Midura, R.J., McQuillan, D.J., Benham, K.J., Fisher, L.W., Hascall, V.C.: A rat osteogenic cell line (UMR 106-01) synthesizes a highly sulfated form of bone sialoprotein. J. Biol. Chem. 265, 5285-5291 (1990) 
62. Zaia, J., Boynton, R., Heinegard, D., Barry, F.: Posttranslational modifications to human bone sialoprotein determined by mass spectrometry. Biochemistry 40, 12983-12991 (2001). doi:10.1021/ bi010887r

63. Ley, K.: The role of selectins in inflammation and disease. Trends Mol. Med. 9, 263-268 (2003). doi:10.1016/S1471-4914(03) 00071-6

64. Magnani, J.L.: The discovery, biology, and drug development of sialyl Lea and sialyl Lex. Arch. Biochem. Biophys. 426, 122-131 (2004). doi:10.1016/j.abb.2004.04.008

65. Hidalgo, A., Frenette, P.S.: Enforced fucosylation of neonatal CD34+ cells generates selectin ligands that enhance the initial interactions with microvessels but not homing to bone marrow. Blood 105, 567-575 (2005). doi:10.1182/blood-2004-03-1026

66. Xia, L., McDaniel, J.M., Yago, T., Doeden, A., McEver, R.P.: Surface fucosylation of human cord blood cells augments binding to Pselectin and E-selectin and enhances engraftment in bone marrow. Blood 104, 3091-3096 (2004). doi:10.1182/blood-2004-02-0650

67. Sackstein, R., Merzaban, J.S., Cain, D.W., Dagia, N.M., Spencer, J. A., Lin, C.P., Wohlgemuth, R.: Ex vivo glycan engineering of CD44 programs human multipotent mesenchymal stromal cell trafficking to bone. Nat. Med. 14, 181-187 (2008). doi:10.1038/nm1703

68. Ruster, B., Gottig, S., Ludwig, R.J., Bistrian, R., Muller, S., Seifried, E., Gille, J., Henschler, R.: Mesenchymal stem cells display coordinated rolling and adhesion behavior on endothelial cells. Blood 108, 3938-3944 (2006). doi:10.1182/blood-2006-05025098
69. Wilkins, P.P., McEver, R.P., Cummings, R.D.: Structures of the Oglycans on P-selectin glycoprotein ligand-1 from HL-60 cells. J. Biol. Chem. 271, 18732-18742 (1996). doi:10.1074/jbc.271. 6.3255

70. Lenter, M., Levinovitz, A., Isenmann, S., Vestweber, D.: Monospecific and common glycoprotein ligands for E- and P-selectin on myeloid cells. J. Cell Biol. 125, 471-481 (1994). doi:10.1083/ jcb.125.2.471

71. Dimitroff, C.J., Lee, J.Y., Fuhlbrigge, R.C., Sackstein, R.: A distinct glycoform of CD44 is an L-selectin ligand on human hematopoietic cells. Proc. Natl. Acad. Sci. U S A 97, 1384113846 (2000). doi:10.1073/pnas.250484797

72. Hennet, T., Chui, D., Paulson, J.C., Marth, J.D.: Immune regulation by the ST6Gal sialyltransferase. Proc. Natl. Acad. Sci. USA 95, 4504-4509 (1998). doi:10.1073/pnas.95.8.4504

73. Takahata, M., Iwasaki, N., Nakagawa, H., Abe, Y., Watanabe, T., Ito, M., Majima, T., Minami, A.: Sialylation of cell surface glycoconjugates is essential for osteoclastogenesis. Bone 41, 7786 (2007). doi:10.1016/j.bone.2007.03.016

74. Priatel, J.J., Chui, D., Hiraoka, N., Simmons, C.J., Richardson, K. B., Page, D.M., Fukuda, M., Varki, N.M., Marth, J.D.: The ST3Gal-I sialyltransferase controls CD8+ T lymphocyte homeostasis by modulating O-glycan biosynthesis. Immunity 12, 273283 (2000). doi:10.1016/S1074-7613(00)80180-6

75. Skelton, T.P., Zeng, C., Nocks, A., Stamenkovic, I.: Glycosylation provides both stimulatory and inhibitory effects on cell surface and soluble CD44 binding to hyaluronan. J. Cell Biol. 140, 431446 (1998). doi:10.1083/jcb.140.2.431 